\title{
Electronic Surveillance and Security Applications of Magnetic Microwires
}

\author{
Valentina Zhukova ${ }^{1,2}{ }^{(D}$, Paula Corte-Leon ${ }^{1,2} \mathbb{D}$, Juan Maria Blanco ${ }^{2}$, Mihail Ipatov ${ }^{1,2}$, Julian Gonzalez $^{1}$ \\ and Arcady Zhukov 1,2,3,*(D)
}

1 Department Advanced Polymers and Materials: Physics, Chemistry and Technology, Faculty of Chemistry, University of Basque Country, UPV/EHU, 20018 San Sebastian, Spain; valentina.zhukova@ehu.es (V.Z.); paula.corte@ehu.eus (P.C.-L.); mihail.ipatov@ehu.es (M.I.); julianmaria.gonzalez@ehu.es (J.G.)

2 Departamento de Física Aplicada, EIG, Basque Country University, Universidad del País Vasco/Euskal Herriko Unibersitatea, UPV/EHU, 20018 San Sebastian, Spain; juanmaria.blanco@ehu.es

3 IKERBASQUE, Basque Foundation for Science, 48011 Bilbao, Spain

* Correspondence: arkadi.joukov@ehu.es; Tel.: +34-94-3018-611; Fax: +34-94-3017-130

Citation: Zhukova, V.; Corte-Leon, P.; Blanco, J.M.; Ipatov, M.; Gonzalez, J.; Zhukov, A. Electronic Surveillance and Security Applications of Magnetic Microwires. Chemosensors 2021, 9, 100. https://doi.org/ $10.3390 /$ chemosensors 9050100

Academic Editors: Raffaele Velotta and Nicole Jaffrezic-Renault

Received: 25 March 2021

Accepted: 28 April 2021

Published: 30 April 2021

Publisher's Note: MDPI stays neutral with regard to jurisdictional claims in published maps and institutional affiliations.

Copyright: (c) 2021 by the authors. Licensee MDPI, Basel, Switzerland. This article is an open access article distributed under the terms and conditions of the Creative Commons Attribution (CC BY) license (https:// creativecommons.org/licenses/by/ $4.0 /)$.

\begin{abstract}
Applications in security and electronic surveillance require a combination of excellent magnetic softness with good mechanical and anticorrosive properties and low dimensionality. We overviewed the feasibility of using glass-coated microwires for electronic article surveillance and security applications, as well as different routes of tuning the magnetic properties of individual microwires or microwire arrays, making them quite attractive for electronic article surveillance and security applications. We provide the routes for tuning the hysteresis loops' nonlinearity by the magnetostatic interaction between the microwires in the arrays of different types of amorphous microwires. The presence of neighboring microwire (either Fe- or Co-based) significantly affects the hysteresis loop of the whole microwires array. In a microwires array containing magnetically bistable microwires, we observed splitting of the initially rectangular hysteresis loop with a number of Barkhausen jumps correlated with the number of magnetically bistable microwires. Essentially, nonlinear and irregular hysteresis loops have been observed in mixed arrays containing Fe- and Co-rich microwires. The obtained nonlinearity in hysteresis loops allowed to increase the harmonics and tune their magnetic field dependencies. On the other hand, several routes allowing to tune the switching field by either postprocessing or modifying the magnetoelastic anisotropy have been reviewed. Nonlinear hysteresis loops have been also observed upon devitrification of amorphous microwires. Semihard magnetic microwires have been obtained by annealing of Fe-Pt-Si microwires. The observed unique combination of magnetic properties together with thin dimensions and excellent mechanical and anticorrosive properties provide excellent perspectives for the use of glass-coated microwires for security and electronic surveillance applications.
\end{abstract}

Keywords: magnetic microwires; magnetic bistability; magnetic tag; electronic surveillance; domain wall propagation; post-processing; magnetic anisotropy; magnetostatic interaction

\section{Introduction}

Soft magnetic materials are an essential part of magnetic sensors and devices demanded by several industries, including (but not limited to) microelectronics, electrical engineering, car, aerospace, and aircraft industries, medicine, magnetic refrigerators, home entertainment, energy harvesting and conversion, informatics, magnetic recording, and security and electronic surveillance [1-3]. In most cases, like in the case of security and electronic surveillance, in addition to excellent magnetic softness, a combination of mechanical and anticorrosive properties and low dimensionality is required [4-6].

Almost all department stores, supermarkets, airports, libraries, museums, etc. are provided with different types of security and anti-thief systems. The principle of elec- 
tronic article surveillance (EAS) systems operation is well established: articles are provided with tags that respond to electromagnetic fields generated by the gates at the store/supermarket/library exits [6]. The response is picked up by the antenna installed on the gate, switching on the alarm.

It is estimated that hundreds of thousands of such EAS systems have been installed and millions of tags are produced daily. Considering the great number of tags, they must be small, robust enough, and inexpensive.

Usually, the magnetic field values generated by the gates are limited by electromagnetic regulations and therefore are quite low, being typically below $100 \mathrm{~A} / \mathrm{m}$. Accordingly, the magnetic materials employed in tags must be magnetically soft enough. However, the magnetic softness of crystalline soft magnetic materials (Permalloy, $\mathrm{Fe}-\mathrm{Si}$ ) is affected by processing. Therefore, amorphous soft magnetic materials, prepared by rapid melt quenching, are considered as among the most suitable materials for tags containing soft magnetic materials $[6,7]$.

Indeed, as a rule, amorphous materials present excellent magnetic softness together with superior mechanical properties [8-12]. Abrupt deterioration of the mechanical properties (such as tensile yield) upon the devitrification of amorphous precursor is reported [12]. Additionally, the fabrication process of amorphous materials involving rapid melt quenching is fast and inexpensive [4-8,10]. Accordingly, amorphous soft magnetic materials are useful for the design of robust magnetic devices and magnetoelastic sensors [13-25].

Different rapid melt quenching methods allow the preparation of amorphous materials of planar (ribbons) or cylindrical (wires) shapes [4-7]. As discussed elsewhere, soft magnetic materials with squared hysteresis loops and relatively low coercivities are the preferred candidates for the EAS systems using magnetic tags [6]. The rectangular hysteresis loops can be easily implemented in different families of amorphous magnetic wires [21-25]. Therefore, considerable attention has been paid to applications of amorphous wires for magnetic tags for different kinds of EAS systems [7,25-29].

The aforementioned squared hysteresis loops of magnetic wires are linked to the peculiar remagnetization process of magnetic wires running through a single and large Barkhausen jump $[6,7,21-25]$. In such magnetic wires, a demagnetized state cannot be achieved $[7,21-23,30-32]$. Accordingly, such magnetic wires are also called magnetically bistable [30-32].

Magnetic wires can be prepared using different techniques involving rapid melt quenching $[7,21-23,33]$. However, glass-coated magnetic microwires prepared by so-called TaylorUlitovsky technique present the widest metallic nucleus diameter range (from $200 \mathrm{~nm}$ up to $100 \mu \mathrm{m}$ ) [34-44]. In this way, the Taylor-Ulitovsky method is the unique technique allowing fabrication of nanowires by rapid melt quenching [34]. On the other hand, the preparation of amorphous magnetic wires with a diameter of about $100 \mu \mathrm{m}$ coated by glass was recently reported [36]. The presence of a flexible, thin, biocompatible and insulating glass coating allows to enhance the corrosive resistance and therefore makes these microwires suitable for novel applications, including biomedicine, electronic article surveillance, nondestructive monitoring external stimuli (stresses, temperature) in smart composites, and construction health monitoring through the microwire inclusions [37-42,45-48]. It is worth noting that, in fact, the Taylor-Ulitovsky technique has been known since the 1960s [43] and has been used for the preparation of amorphous microwires since the 1970s [44]. The modern Taylor-Ulitovsky technique is suitable for the preparation of continuous glass-coated microwires of up to $10 \mathrm{~km}$ long, and roughly $1 \mathrm{~km}$ of microwire can be prepared from $1 \mathrm{~g}$ of metallic alloys $[36,45]$.

The relevant advantage of the Taylor-Ulitovsky technique allowing the preparation of glass-coated microwires is that the metallic nucleus diameter could be significantly reduced (typically by an order of magnitude). Such diameter decrease is especially relevant for magnetically bistable wires, because a perfectly rectangular hysteresis loop is only observed for wires having a minimum length. Thus, in Fe-rich amorphous wires with diameters of about $120 \mu \mathrm{m}$, such minimum length, $L_{m}$, for observation of rectangular hysteresis loop is about $7 \mathrm{~cm}$ [31]. For the wire (with diameter of $120 \mu \mathrm{m}$ ) lengths below 
$7 \mathrm{~cm}$, magnetically bistable behavior cannot be observed [31]. For glass-coated microwires with typical diameters of $10-15 \mu \mathrm{m}$, such $L_{m}$ is typically of a few millimeters $[22,25,47,48]$. Accordingly, glass-coated microwires prepared by the Taylor-Ulitovsky technique have a clear advantage: the magnetic tag size can be drastically reduced $[22,25]$.

Accordingly, considering dimensionality and the combination of physical properties (magnetic, mechanical, and corrosive), amorphous soft magnetic microwires are potentially suitable materials for electronic article surveillance and security applications. There are several original papers and patents dealing with rather different (multi-bit or singlebit) security and EAS applications of magnetic wires [25-29,47,48]. However, to our best knowledge, there are no reviews summarizing published experimental results and analyzing trends in security and EAS applications of magnetic microwires. Consequently, in this paper we will provide an overview of the trends related to EAS and security applications of glass-coated magnetic microwires.

This paper is organized as follows. In Section 2, the experimental methods as well as the microwires characteristics analyzed in this review are provided. Section 3 deals with results on feasibility of using magnetic microwires for magnetic tags, followed by overview of tuning of hysteresis loop nonlinearity by the magnetostatic interaction between microwires and then by multi-bit magnetic tags applications of magnetic microwires.

\section{Materials and Methods}

Fe-, Co-, and Ni-rich glass-coated amorphous microwires have been prepared by Taylor-Ulitovsky preparation method, described in details elsewhere (the compositions and diameters of microwires are provided in Table 1) [36,45].

Table 1. Compositions and geometry of studied glass-coated microwires.

\begin{tabular}{|c|c|c|c|c|}
\hline Composition & $\begin{array}{l}\text { Ietallic Nucleus Diameter, } \\
\qquad d(\mu \mathrm{m})\end{array}$ & $\begin{array}{l}\text { Total Diameter, } \\
\qquad D(\mu \mathrm{m})\end{array}$ & $\begin{array}{c}\text { Ratio } \\
\rho=d / D\end{array}$ & $\begin{array}{c}\text { Magnetostriction } \\
\text { Coefficient, } \\
\lambda_{s} \times 10^{6}\end{array}$ \\
\hline $\mathrm{Fe}_{74} \mathrm{~B}_{13} \mathrm{Si}_{11} \mathrm{C}_{2}$ & 10 & 20 & 0.5 & 38 \\
\hline $\mathrm{Fe}_{74} \mathrm{~B}_{13} \mathrm{Si}_{11} \mathrm{C}_{2}$ & 12.3 & 15 & 0.82 & 38 \\
\hline $\mathrm{Fe}_{74} \mathrm{~B}_{13} \mathrm{Si}_{11} \mathrm{C}_{2}$ & 17.3 & 28.2 & 0.61 & 38 \\
\hline $\mathrm{Fe}_{74} \mathrm{~B}_{13} \mathrm{Si}_{11} \mathrm{C}_{2}$ & 19.4 & 26.6 & 0.73 & 38 \\
\hline $\mathrm{Fe}_{75} \mathrm{~B}_{9} \mathrm{Si}_{12} \mathrm{C}_{4}$ & 15.2 & 17.2 & 0.88 & 38 \\
\hline $\mathrm{Fe}_{65} \mathrm{Si}_{15} \mathrm{~B}_{15} \mathrm{C}_{5}$ & 12.6 & 20 & 0.63 & 38 \\
\hline $\mathrm{Fe}_{65} \mathrm{Si}_{15} \mathrm{~B}_{15} \mathrm{C}_{5}$ & 15 & 23.8 & 0.63 & 38 \\
\hline $\mathrm{Fe}_{65} \mathrm{Si}_{15} \mathrm{~B}_{15} \mathrm{C}_{5}$ & 10.8 & 22.5 & 0.48 & 38 \\
\hline $\mathrm{Fe}_{65} \mathrm{Si}_{15} \mathrm{~B}_{15} \mathrm{C}_{5}$ & 6 & 23.1 & 0.26 & 38 \\
\hline $\mathrm{Fe}_{65} \mathrm{Si}_{15} \mathrm{~B}_{15} \mathrm{C}_{5}$ & 3 & 18.75 & 0.16 & 38 \\
\hline $\mathrm{Fe}_{77.5} \mathrm{Si}_{7.5} \mathrm{~B}_{15}$ & 15.1 & 35.8 & 0.42 & 38 \\
\hline $\mathrm{Co}_{69.2} \mathrm{Fe}_{3.6} \mathrm{Ni}_{1} \mathrm{~B}_{12.5} \mathrm{Si}_{11} \mathrm{C}_{1.2} \mathrm{Mo}_{1.5}$ & 22.8 & 23.2 & 0.98 & -1 \\
\hline $\mathrm{Co}_{67} \mathrm{Fe}_{3.9} \mathrm{Ni}_{1.5} \mathrm{~B}_{11.5} \mathrm{Si}_{14.5} \mathrm{Mo}_{1.6}$ & 29.2 & 31 & 0.94 & -0.5 \\
\hline $\mathrm{Fe}_{71.7} \mathrm{~B}_{13.4} \mathrm{Si}_{11} \mathrm{Nb}_{3} \mathrm{Ni}_{0.9}$ & 103 & 158 & 0.65 & 35 \\
\hline $\mathrm{Co}_{69.2} \mathrm{Fe}_{4.1} \mathrm{~B}_{11.8} \mathrm{Si}_{13.8} \mathrm{C}_{1.1}$ & 25.6 & 30.2 & 0.85 & -0.03 \\
\hline $\mathrm{Co}_{64.04} \mathrm{Fe}_{5.71} \mathrm{~B}_{15.88} \mathrm{Si}_{10.94} \mathrm{Cr}_{3.4} \mathrm{Ni}_{0.3}$ & 94 & 126 & 0.75 & 2 \\
\hline $\mathrm{Fe}_{16} \mathrm{Co}_{60} \mathrm{Si}_{13} \mathrm{~B}_{11}$ & 12 & 29 & 0.41 & 15 \\
\hline $\mathrm{Fe}_{62} \mathrm{Ni}_{15.5} \mathrm{Si}_{7.5} \mathrm{~B}_{15}$ & 14.35 & 33.25 & 0.43 & 27 \\
\hline $\mathrm{Fe}_{47.4} \mathrm{Ni}_{26.6} \mathrm{Si}_{11} \mathrm{~B}_{13} \mathrm{C}_{2}$ & 29 & 32.2 & 0.9 & 20 \\
\hline $\mathrm{Fe}_{49.6} \mathrm{Ni}_{27.9} \mathrm{Si}_{7.5} \mathrm{~B}_{15}$ & 14.2 & 33.85 & 0.42 & 20 \\
\hline $\mathrm{Fe}_{71.8} \mathrm{Cu}_{1} \mathrm{Nb}_{3.1} \mathrm{Si}_{15} \mathrm{~B}_{9.1}$ & 7.0 & 24.8 & 0.282 & 30 \\
\hline $\mathrm{Fe}_{71.8} \mathrm{Cu}_{1} \mathrm{Nb}_{3.1} \mathrm{Si}_{15} \mathrm{~B}_{9.1}$ & 18.2 & 39 & 0.467 & 30 \\
\hline $\mathrm{Fe}_{70.8} \mathrm{Cu}_{1} \mathrm{Nb}_{3.1} \mathrm{Si}_{14.5} \mathrm{~B}_{10.6}$ & 5.8 & 15.2 & 0.38 & 30 \\
\hline $\mathrm{Fe}_{38.5} \mathrm{Co}_{38.5} \mathrm{~B}_{18} \mathrm{Mo}_{4} \mathrm{Cu}_{1}$ & 10 & 16.6 & 0.6 & \\
\hline $\mathrm{Fe}_{50} \mathrm{Pt}_{40} \mathrm{Si}_{10}$ & 8 & 21 & 0.38 & \\
\hline
\end{tabular}


The provided microwires geometry ( $d$ - and $D$-values) gives the average values determined by the optical microscopy at several places of the microwires. Typically, the spread in $d$ - and $D$-values is below $0.5 \mu \mathrm{m}$ [5].

Generally, we analyzed three different types of magnetic microwires: (i) amorphous microwires with high, positive magnetostriction coefficients, $\lambda_{s}$, (Fe-Si-B-C, Fe-Ni-Si-B-C, $\mathrm{Fe}-\mathrm{Co}-\mathrm{Si}-\mathrm{B}, \mathrm{Fe}-\mathrm{B}-\mathrm{Si}-\mathrm{Nb}-\mathrm{Ni}$, or $\mathrm{Fe}-\mathrm{Ni}-\mathrm{Si}-\mathrm{B})$, (ii) amorphous microwires with vanishing $\lambda_{s}(\mathrm{Co}-\mathrm{Fe}-\mathrm{Ni}-\mathrm{B}-\mathrm{Si}-\mathrm{Mo}, \mathrm{Co}-\mathrm{Fe}-\mathrm{B}-\mathrm{Si}-\mathrm{Cr}-\mathrm{Ni}$, or $\mathrm{Co}-\mathrm{Fe}-\mathrm{B}-\mathrm{Si}-\mathrm{C})$, or (iii) partially crystalline (nanocrystalline) ( $\mathrm{Fe}-\mathrm{Cu}-\mathrm{Nb}-\mathrm{Si}-\mathrm{B}, \mathrm{Fe}-\mathrm{Co}-\mathrm{B}-\mathrm{Mo}-\mathrm{Cu}$, or $\mathrm{Fe}-\mathrm{Pt}-\mathrm{Si}$ ) microwires.

The amorphous structure of all the microwires has been proved by the X-ray diffraction (XRD) method. All amorphous microwires present a broad halo in the XRD patterns. The XRD patterns have been obtained by the Bruker (D8 Advance) X-ray diffractometer with $\mathrm{Cu} \mathrm{K} \alpha(\lambda=1.54 \AA)$ radiation. Several samples have been annealed in a conventional furnace at temperatures below the crystallization temperature. Typically, the crystallization of amorphous microwires was observed at $T_{\text {ann }} \geq 500{ }^{\circ} \mathrm{C}$ [49].

The induction method previously was used for the hysteresis loops measurements. The details of the experimental set-up are described in details elsewhere [46]. The hysteresis loops were represented as the magnetic field, $H$, dependence of the normalized magnetization, $M / M_{0}$, where $M$ is the magnetic moment at a given magnetic field, and $M_{0}$ is the magnetic moment at the maximum magnetic field amplitude, $H_{m}$. Such hysteresis loops are useful for comparison of the samples with different chemical compositions (hence, different saturation magnetization).

In several cases, the hysteresis loops were measured with a conventional superconducting quantum interference device, SQUID.

The magnetostriction coefficients, $\lambda_{s}$, of the investigated microwires, were evaluated using the SAMR method adapted for microwires, as described elsewhere $[46,49]$.

The experimental set-up allowing to measure the electromagnetic response of a magnetic tag consisting of an exciting coil, a pick-up coil, a preamplifier, and registration facilities is described elsewhere (see Figure 1) [47].

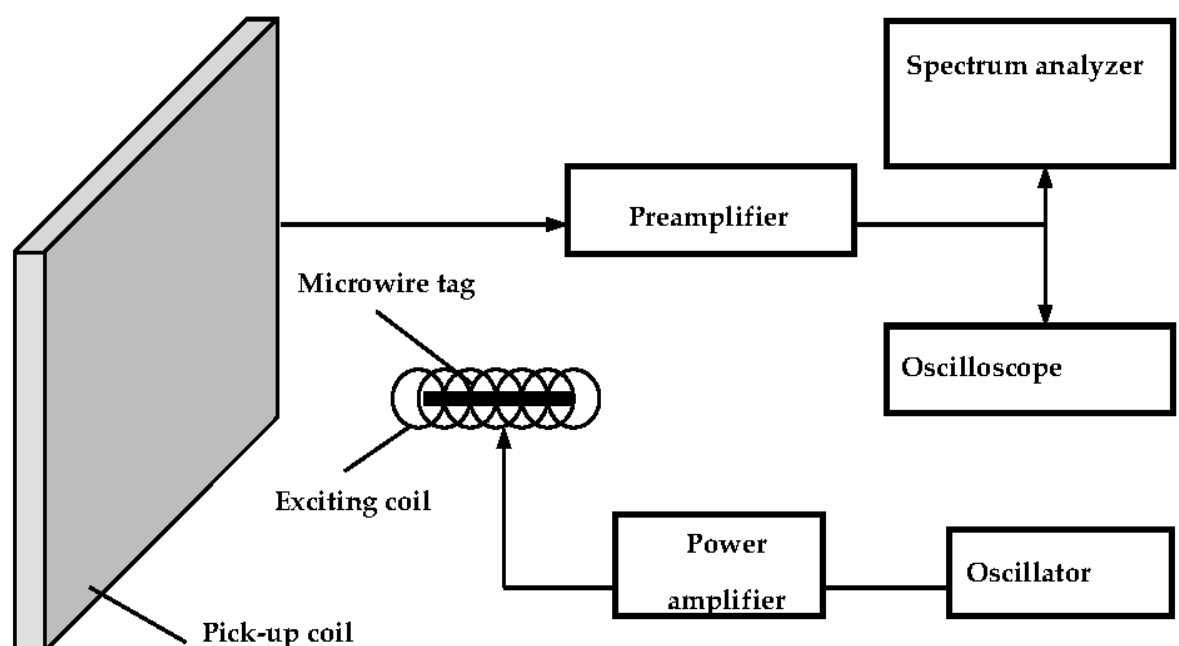

Figure 1. Scheme of experimental set-up designed to detect the electromagnetic signals of the magnetic labels. Reprinted with permission from [47].

The magnetic tag (up to $4 \mathrm{~cm}$ long) is magnetized by $5 \mathrm{~cm}$ long exciting coil producing a nearly uniform magnetic field up to $640 \mathrm{~A} / \mathrm{m}$ with frequency $f=332 \mathrm{~Hz}$. We used a squared pick-up coil containing 20 turns with a side of $20 \mathrm{~cm}$. An exciting coil with a magnetic tag inside was located perpendicular to the pick-up coil plane. The electromagnetic signal from the tag was amplified by a preamplifier with a voltage gain $~ 100$ and detected by the registration facilities, i.e., spectrum analyzer CF 5210 and a digital oscilloscope. The noise voltage level at a frequency higher than $1 \mathrm{kHz}$ is given by $\sim 10 \mu \mathrm{V} / \mathrm{Hz}^{1 / 2}$. The tag placed 
inside the exciting coil produces a periodic signal of negative and positive pulses detected in the digital oscilloscope.

We also measured the amplitudes of the first seven harmonics of the voltage induced in the pick-up coil using a lock-in amplifier. For these measurements, the fundamental frequency was $200 \mathrm{~Hz}$.

\section{Results}

\subsection{Feasibility of Using Magnetic Microwires for Magnetic Tags}

For magnetic tag applications, the magnetic response must be as high as possible. Fe-rich microwires present a higher saturation magnetization. Additionally, as-prepared Fe-rich microwires have perfectly rectangular hysteresis loops (see Figure 2a). To assess the feasibility of using Fe-rich microwires for magnetic tags, we measured the fifth harmonic as a function of the distance between the tag and the pick-up coil. As can be seen from Figure 2b, the fifth harmonic of $3 \mathrm{~cm}$ long $\mathrm{Fe}_{74} \mathrm{~B}_{13} \mathrm{Si}_{11} \mathrm{C}_{2}$ microwire (metallic nucleus diameter, $d=17.3 \mu \mathrm{m}$ ) can be detected at a distance up to $25 \mathrm{~cm}$. Similar studies of Fe-rich microwires with $d \approx 100 \mu \mathrm{m}$ show that in this case, the signal can be detected at a distance up to $50 \mathrm{~cm}$ [48].

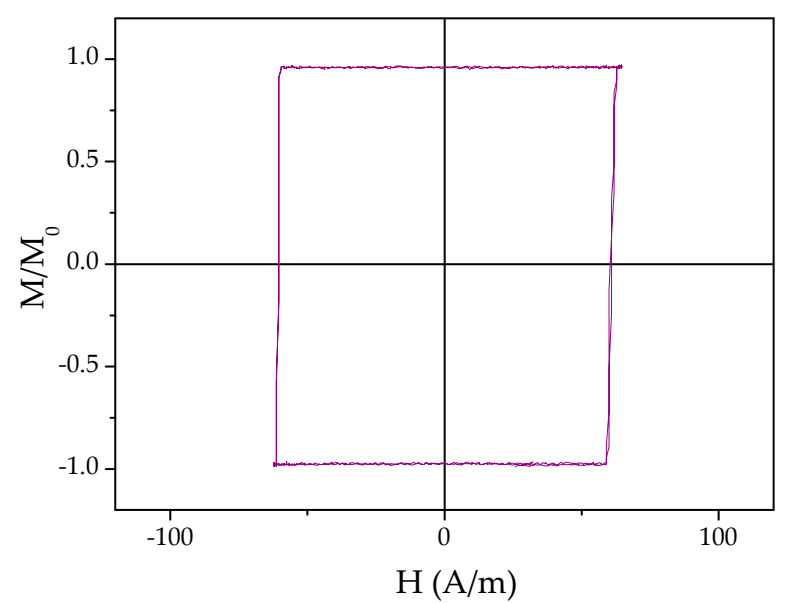

(a)

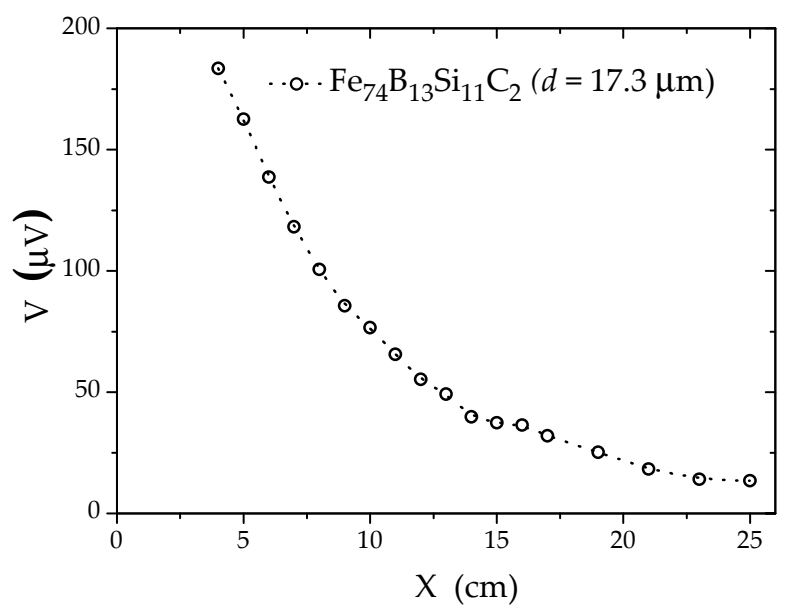

(b)

Figure 2. Hysteresis loop (a) and the amplitudes of the fifth harmonics generated by a $3 \mathrm{~cm} \mathrm{long} \mathrm{Fe}_{74} \mathrm{~B}_{13} \mathrm{Si}_{11} \mathrm{C}_{2}$ microwire with diameter $d=17.3 \mu \mathrm{m}$ as a function of the distance from the pick-up coil (b). Figure $2 \mathrm{~b}$ is adapted [47].

Perfectly rectangular hysteresis loops of Fe-rich microwires are quite stable: the character of hysteresis loops remains the same even after long annealing (180 $\mathrm{min})$ at an elevated annealing temperature, $T_{a n n}=400{ }^{\circ} \mathrm{C}$ (see Figure 3a,b).

Only slight coercivity, $H_{c}$, decrease is observed upon annealing at $T_{a n n}=400{ }^{\circ} \mathrm{C}$ (Figure 3c). The crystallization temperature of the $\mathrm{Fe}_{74} \mathrm{~B}_{13} \mathrm{Si}_{11} \mathrm{C}_{2}$ microwire is about $522^{\circ} \mathrm{C}$ [49]. Therefore, a slight coercivity decrease must be associated with internal stresses relaxation. On the other hand, quite sharp voltage peaks (about $10 \mu \mathrm{s}$ ) in the pick-up coils are produced upon magnetization switching in such Fe-rich microwires (Figure 3d).

\subsection{Tuning of Hysteresis Loop Nonlinearity by the Magnetostatic Interaction between Microwires}

Magnetic tags applications require a nonlinear hysteresis loop that contains the characteristic distribution of harmonic frequencies. It is believed that the steeper the magnetization reversal, the higher the harmonic content of the signal. Accordingly, perfectly rectangular hysteresis loops with low coercivity observed in Fe-rich microwires (Figures 2 and 3 ) are attractive for use as magnetic tags. 

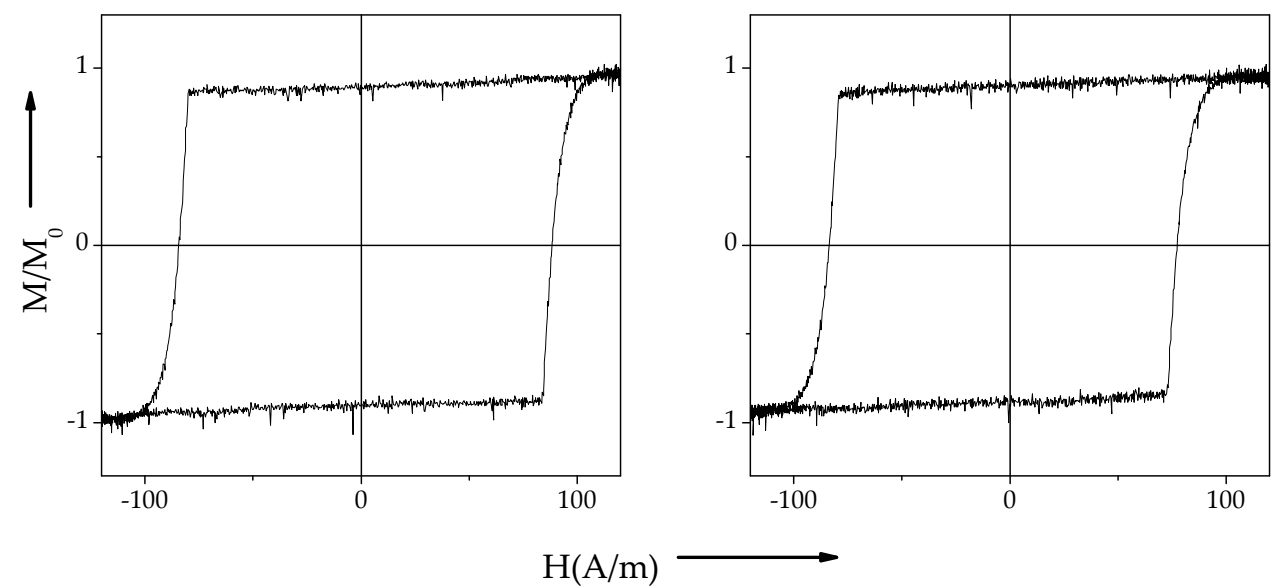

(a)

$\mathrm{H}(\mathrm{A} / \mathrm{m})$

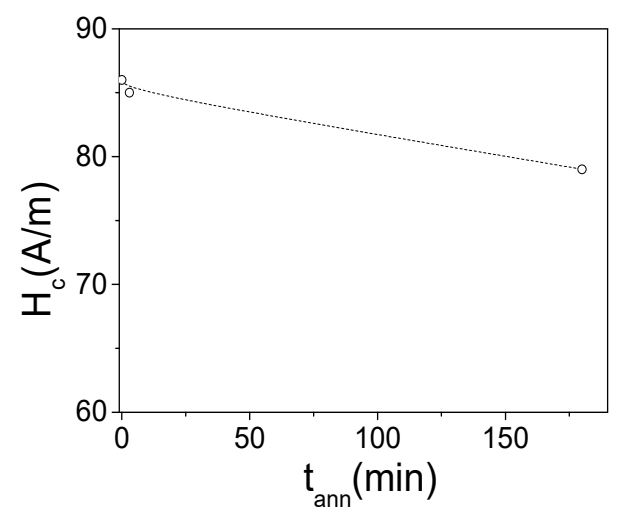

(c)

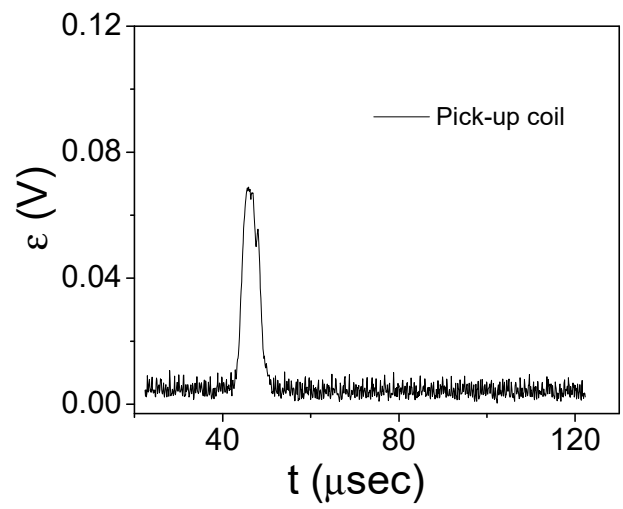

(d)

Figure 3. Hysteresis loops of as-prepared (a) and annealed at $T_{\text {ann }}=400{ }^{\circ} \mathrm{C}$ for 180 min (b) $\mathrm{Fe}_{75} \mathrm{~B}_{9} \mathrm{Si}_{12} \mathrm{C}_{4}$ microwires; dependence of coercivity on annealing time (c) and the time dependence of the EMF signal in the pick-up coil of as-prepared $\mathrm{Fe}_{75} \mathrm{~B}_{9} \mathrm{Si}_{12} \mathrm{C}_{4}$ microwire (d).

On the other hand, the nonlinearity of the hysteresis loop of the magnetic microwires can be further improved using the magnetostatic interaction of microwires. Below, we will present several experimental results on magnetic response of two kinds of individual microwires $\left(\mathrm{Co}_{67} \mathrm{Fe}_{3.9} \mathrm{Ni}_{1.5} \mathrm{~B}_{11.5} \mathrm{Si}_{14.5} \mathrm{Mo}_{1.6}\right.$ and $\left.\mathrm{Fe}_{74} \mathrm{~B}_{13} \mathrm{Si}_{11} \mathrm{C}_{2}\right)$ as well as the arrays containing either microwires of the same type or containing two different kinds of microwires. Microwires in each array were located close to each other, that is, the magnetic nucleuses were separated only by the glass coatings.

The hysteresis loops of such microwires are rather different: microwire with high and positive magnetostriction coefficient, $\lambda_{s}$, exhibits perfectly a rectangular hysteresis loop with $H_{c} \approx 100 \mathrm{~A} / \mathrm{m}$ (Figure $4 \mathrm{a}$ ), however, an inclined hysteresis loop with quite low $H_{c}$ $\left(H_{c} \approx 5 \mathrm{~A} / \mathrm{m}\right)$ is observed in $\mathrm{Co}_{67} \mathrm{Fe}_{3.9} \mathrm{Ni}_{1.5} \mathrm{~B}_{11.5} \mathrm{Si}_{14.5} \mathrm{Mo}_{1.6}$ microwires (see Figure $4 \mathrm{~b}$ ). 


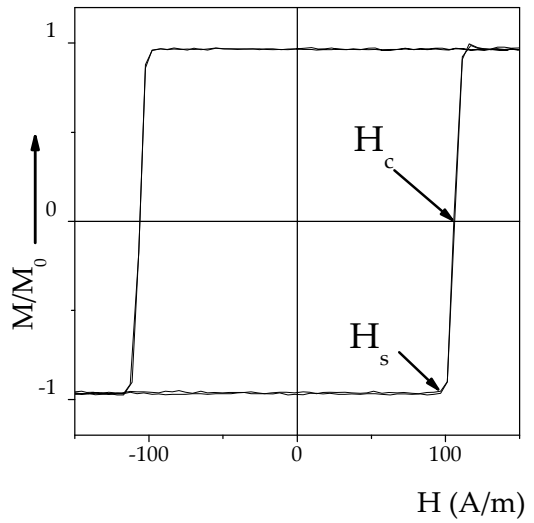

(a)

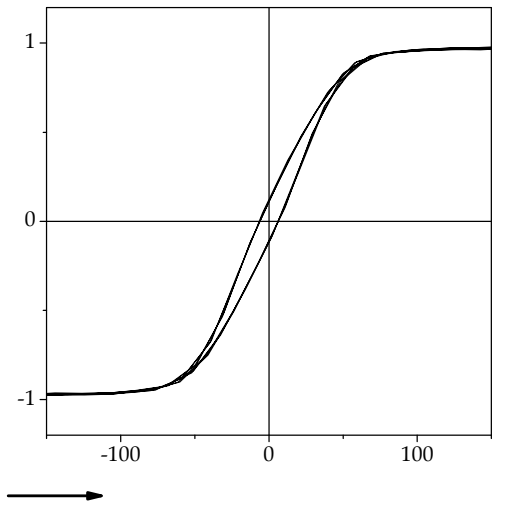

(b)

Figure 4. Hysteresis loops of $\mathrm{Fe}_{75} \mathrm{~B}_{9} \mathrm{Si}_{12} \mathrm{C}_{4}$ microwires with positive (a) and $\mathrm{Co}_{67} \mathrm{Fe}_{3.9} \mathrm{Ni}_{1.5} \mathrm{~B}_{11.5} \mathrm{Si}_{14.5} \mathrm{Mo}_{1.6}$ with vanishing $(\mathbf{b})$ magnetostriction coefficients.

As discussed elsewhere, the hysteresis loop of even individual Fe-rich magnetically bistable microwires is remarkably affected by the magnetic field amplitude. The most relevant hysteresis loop change in a single Fe-rich magnetically bistable microwire takes place when the magnetic field amplitude, $H_{0}$, exceeds the switching field, $H_{s}$, value [50,51]: below certain "critical" magnetic field amplitude, $H_{c, c r i t}$, value (for studied $\mathrm{Fe}_{75} \mathrm{~B}_{9} \mathrm{Si}_{12} \mathrm{C}_{4}$ microwire at $H_{c, \text { crit }} \approx 100 \mathrm{~A} / \mathrm{m}$ ), the hysteresis loop abruptly disappears (see Figure 5a). Above $H_{c, c r i t}$, the magnetization switching by single and large Barkhausen jump occurs. Accordingly, such critical magnetic field is commonly referred to as the aforementioned switching field, $H_{s}$, at which the irreversible magnetization switching begins. It is worth noting that in $\mathrm{AC}$ hysteresis loops at low $H_{0}$ and magnetic field frequency, $f, H_{s} \approx H_{\mathcal{c}}$ (see Figures $4 \mathrm{a}$ and $5 \mathrm{a}$ ). However, with increasing $H_{0}$, one can observe a deviation from the perfectly rectangular hysteresis loop typical of magnetically bistable Fe-based microwires (Figure 5a). This modification of the hysteresis loop shape (more noticeable for high $H_{0}$-values) was explained by taking into account the counterbalance between the sweep rate, $d H / d t$, and the magnetization switching time required for single domain wall (DW) propagation over the sample [50,52]. In the case of a triangular input signal, $d H / d t$ is given as the following equation [52]:

$$
d H / d t=4 f H_{0}
$$

Accordingly, increasing of $H_{0}$ or $f$ results in faster sweep rate, $d H / d t$.

Such change of the hysteresis loops is linked with $H_{c}$ increase. Previously, the frequency and magnetic field amplitude dependence of coercivity in various magnetic materials has been described as follows [52,53]:

$$
H_{c}=H_{c o}+B\left(f H_{0}\right)^{1 / n}
$$

where $H_{c o}$ is the static coercivity, $H_{0}$ is the magnetic field amplitude, and $n$ is a coefficient ranging from 1 to 4 , which depends on the sample geometry and the type of the hysteresis loop of the studied materials, and $B$-a coefficient depending on the intrinsic material parameters [52,53]. 


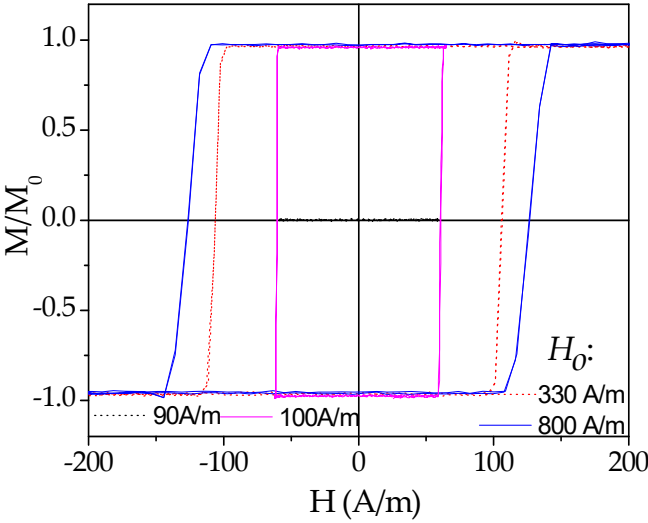

(a)

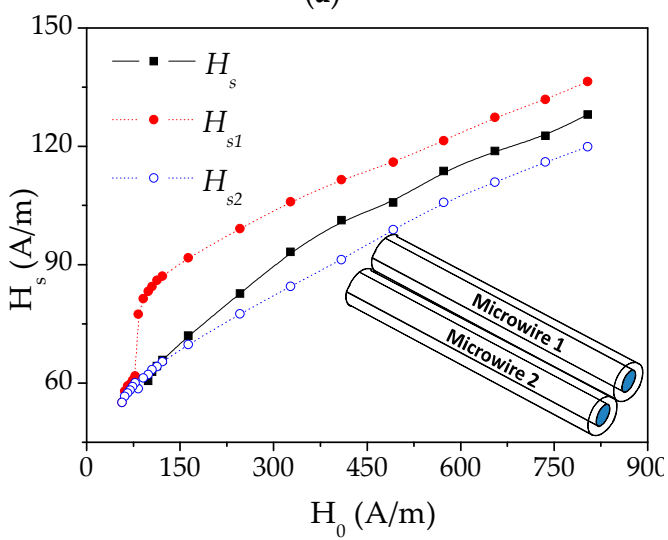

(c)

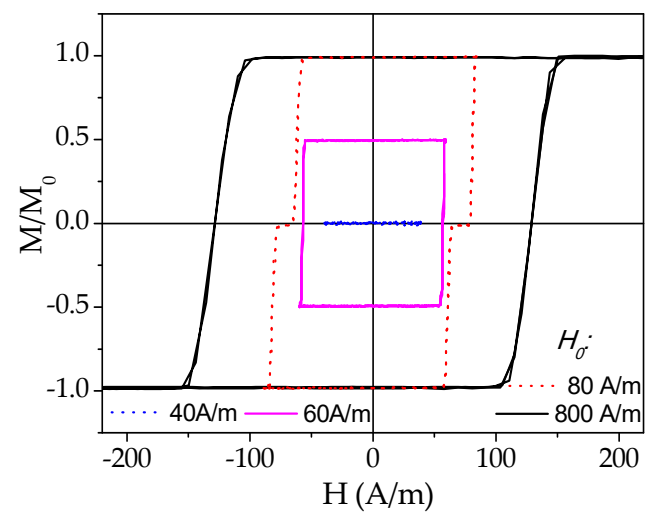

(b)

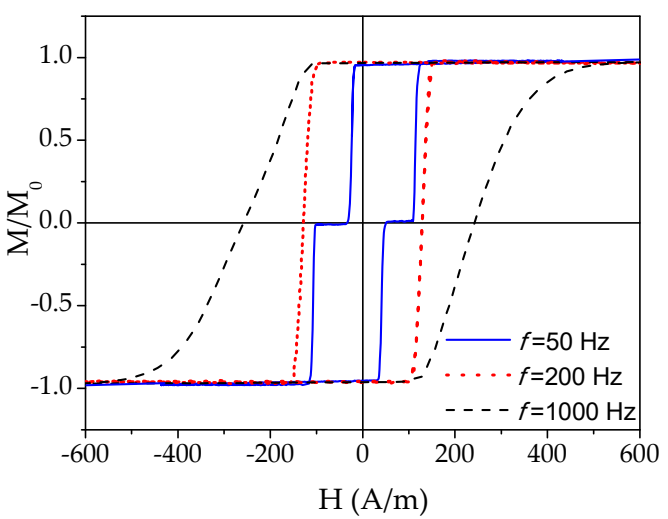

(d)

Figure 5. Hysteresis loops measured at different magnetic field amplitudes, $H_{0}$, for a single glass-coated $\mathrm{Fe}_{74} \mathrm{~B}_{13} \mathrm{Si}_{11} \mathrm{C}_{2}$ microwire $(d=19.4 \mu \mathrm{m})(\mathbf{a})$, and array with two microwires $(\mathbf{b})$; dependence of switching field, $H_{s}$, on $H_{0}$ for a single microwire (solid line) and for an array containing 2 microwires, $H_{s 1}$ and $H_{s 2}$ (dot-line) (c); hysteresis loops of the two microwires measured at different magnetic field frequencies, $f(\mathbf{d})$. The schematic picture of the microwires array is provided in the inset of (c). Reprinted with permission from [50].

Additionally, even the switching field, $H_{s}$, increases with increasing $H_{0}$ and $f$ (see Figure 5a). However, $H_{s}$ increases slower than $H_{c}$ with increasing $H_{0}$ and $f$ (see Figure 5a for $\left.H_{0}\right)$. The origin of such $H_{c}(f), H_{s}(f), H_{c}\left(H_{0}\right)$, and $H_{s}\left(H_{0}\right)$ dependencies has been discussed considering a reversible magnetization process associated with reversible DW movement at low magnetic field (below magnetization switching) and the irreversible DW movement associated to large and single Barkhausen jump [52,53].

The hysteresis loop of an array containing two $\mathrm{Fe}_{74} \mathrm{~B}_{13} \mathrm{Si}_{11} \mathrm{C}_{2}$ microwires is rather different from that of a single $\mathrm{Fe}_{74} \mathrm{~B}_{13} \mathrm{Si}_{11} \mathrm{C}_{2}$ microwire. Two Barkhausen jumps can be observed at $H_{0}>80 \mathrm{~A} / \mathrm{m}$ (see Figure 5b). Such peculiar hysteresis loop shape has been explained by considering the magnetostatic interaction in the two-microwire array $[50,51]$. Such magnetostatic interaction is a consequence of stray fields created by magnetically bistable microwires: the superposition of external and stray fields causes magnetization reversal in one of the samples, when the external field is below the switching field of a single microwire. Single rectangular hysteresis loop (similar to the case of single microwire shown in Figure 5a) is observed for $60 \mathrm{~A} / \mathrm{m}<H_{0}<80 \mathrm{~A} / \mathrm{m}$ (see Figure 5b).

In the array consisting of two microwires, the lower switching field of the first Barkhausen jump, $H_{s 1}$, decreases, while the switching field of the second Barkhausen jump, $H_{s 2}$, increases (Figure $5 \mathrm{c}$ ). Such difference must be attributed to the stray field created by neighboring microwire [50,51]. The origin of the different $H_{S}$-values of individual microwires can be related with metallic nucleus diameters or glass-coating thickness fluctuations, stresses induced by cutting, and so forth. 
At an increasing magnetic field amplitude (approximately at $H_{0}>250 \mathrm{~A} / \mathrm{m}$ ), this splitting of the hysteresis loop disappears (Figure 5d). Such dependence of the hysteresis loop of two microwires array can be understood from the counterbalance between the $d H / d t$ and the switching time determined by the velocity of the DW propagation along the whole wire.

As can be appreciated from Equation (2), $H_{c}$ is also affected by the frequency, $f$. Accordingly, $H_{c}$, as well as overall hysteresis loops of the two-microwires array are affected by $f$ in a similar way as by $H_{0}$ (see Figure $5 c, d$ ). For a two-microwires array, two-steps hysteresis loops are observed for $f<150 \mathrm{~Hz}$. At $f>150 \mathrm{~Hz}$, the hysteresis loop splitting disappears, and at $150<f<1000 \mathrm{~Hz}$, a single smooth magnetization jump is observed.

Accordingly, the odd and even harmonics of the signal of two Fe-rich microwires array are affected by $H_{0}$ and $f$ (see Figure $6 \mathrm{a}, \mathrm{b}$ ).

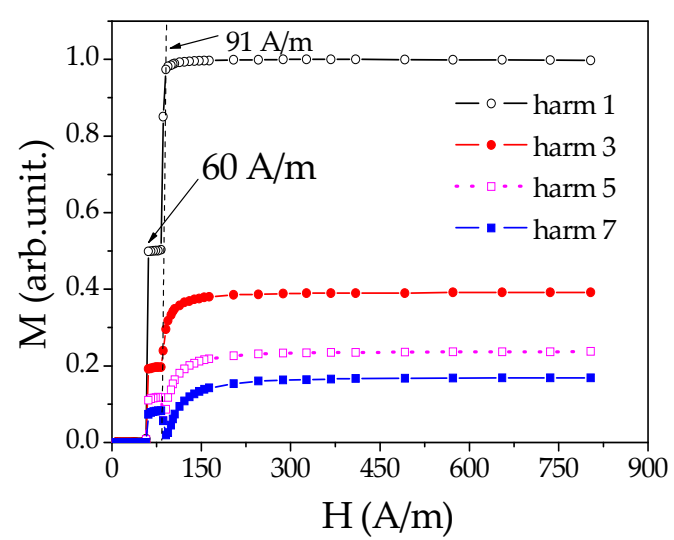

(a)

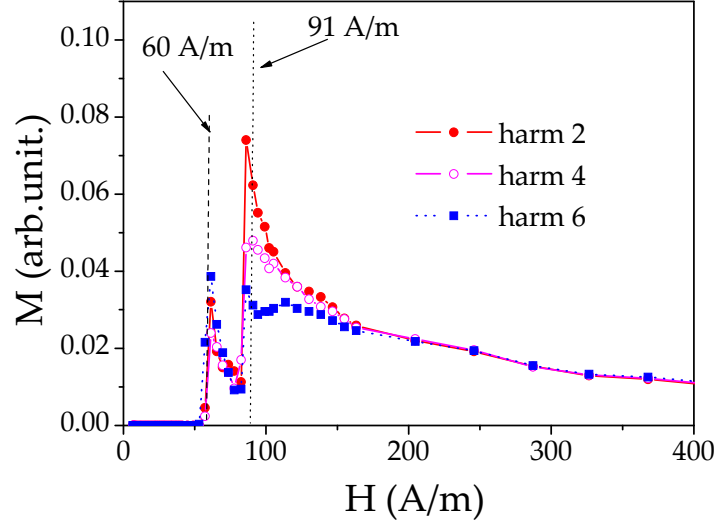

(b)

Figure 6. Dependences of odd harmonics (a) and even harmonics (b) on magnetic field amplitude in $\mathrm{Fe}_{74} \mathrm{~B}_{13} \mathrm{Si}_{11} \mathrm{C}_{2}$ microwires $(d=19.4 \mu \mathrm{m})$. Reprinted with permission from [51].

A sharp increase in the harmonics amplitudes is observed when $H_{0}$ exceeds $H_{s 1}$ and $H_{s 2}$ (see Figure $6 \mathrm{a}, \mathrm{b}$ ). The even harmonics amplitudes are significantly inferior to the odd harmonics amplitudes. The field dependences of odd harmonics have a "plateau" between 60 and $90 \mathrm{~A} / \mathrm{m}$, which reflects the hysteresis loops splitting (see Figure 6a).

Another example of tuning the nonlinearity of hysteresis loops and harmonics is the magnetostatic interaction of microwires with different character of hysteresis loops. Rather nonlinear hysteresis loops can be obtained in an array consisting of one $\mathrm{Fe}_{74} \mathrm{~B}_{13} \mathrm{Si}_{11} \mathrm{C}_{2}$ and one $\mathrm{Co}_{67} \mathrm{Fe}_{3.9} \mathrm{Ni}_{1.5} \mathrm{~B}_{11.5} \mathrm{Si}_{14.5} \mathrm{Mo}_{1.6}$ microwire (see Figure 7a). In such array, at $H_{0}<90 \mathrm{~A} / \mathrm{m}$ (which corresponds to $H_{S}$ of $\mathrm{Fe}_{74} \mathrm{~B}_{13} \mathrm{Si}_{11} \mathrm{C}_{2}$ microwire), the hysteresis loops character is typical of those for a single $\mathrm{Co}_{67} \mathrm{Fe}_{3.9} \mathrm{Ni}_{1.5} \mathrm{~B}_{11.5} \mathrm{Si}_{14.5} \mathrm{Mo}_{1.6}$ microwire. Essentially, nonlinear hysteresis loops have been observed at $H_{0}>110 \mathrm{~A} / \mathrm{m}$ (Figure 7a). Such peculiar hysteresis loops can be interpreted as the superposition of two hysteresis loops: one from magnetically bistable $\mathrm{Fe}_{74} \mathrm{~B}_{13} \mathrm{Si}_{11} \mathrm{C}_{2}$ microwire (shown in Figure $4 \mathrm{a}$ ) and the other one from $\mathrm{Co}_{67} \mathrm{Fe}_{3.9} \mathrm{Ni}_{1.5} \mathrm{~B}_{11.5} \mathrm{Si}_{14.5} \mathrm{Mo}_{1.6}$ microwire with linear hysteresis loop (shown in Figure $4 \mathrm{~b}$ ). At intermediate $H_{0}$-values, the shape of the hysteresis loop depends on $H_{0}$. 


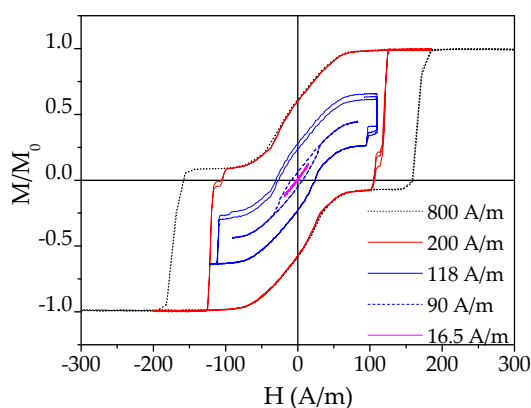

(a)

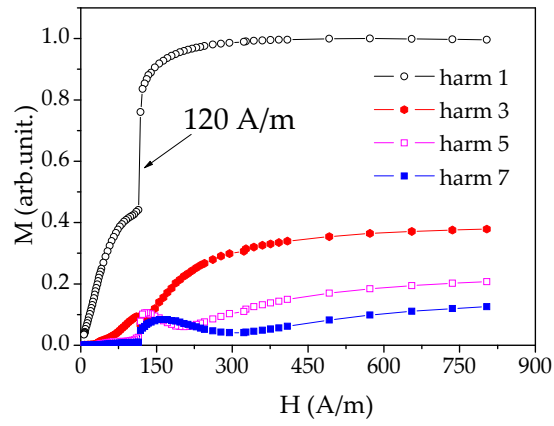

(b)

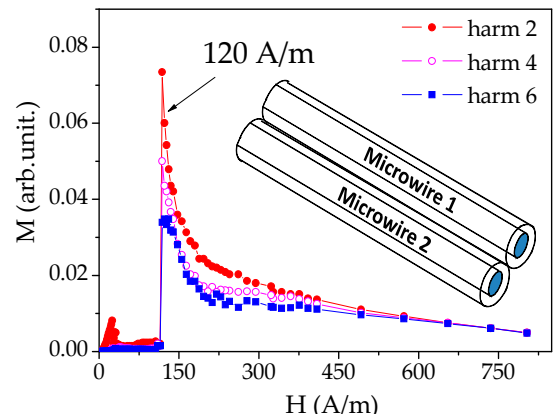

(c)

Figure 7. (a) Hysteresis loops of the $\mathrm{Fe}_{74} \mathrm{~B}_{13} \mathrm{Si}_{11} \mathrm{C}_{2}(d=19.4 \mu \mathrm{m})+\mathrm{Co}_{67} \mathrm{Fe}_{3.9} \mathrm{Ni}_{1.5} \mathrm{~B}_{11.5} \mathrm{Si}_{14.5} \mathrm{Mo}_{1.6}$ array; (b) dependences of odd harmonics on magnetic field amplitude and (c) dependences of even harmonics on magnetic field amplitude. The schematic picture of the microwires array is provided in the inset of (c). Reprinted with permission from [50].

The peculiar hysteresis loop character at $H_{0} \leq 120 \mathrm{~A} / \mathrm{m}$ can be explained by the partial magnetization reversal of the magnetically bistable wire under the influence of the stray field from the Co-based wire. The stray field is affected by the sample demagnetizing factor and the sample magnetization [54,55]. In the case of Co-rich microwire, the magnetization and hence, the stray field are affected by the applied magnetic field (as can be appreciated from the hysteresis loops shown in Figure $4 \mathrm{~b}$ ). In contrast, the magnetization of Fe-rich sample change by abrupt jump and below and above $H_{S}$ is almost independent of magnetic field (see Figure 4a).

Accordingly, such microwire array consisting of two microwires (Fe-rich and Co-rich) with different hysteresis loops presents odd and even harmonics quite different from the case of the array with two Fe-rich microwires (see Figure 7b,c). A single, sharp jump of odd and even harmonics is observed at $H_{0} \approx H_{s}$. There is also a change in the odd and even harmonics in the weak $\left(H_{0}<H_{s}\right)$ field region (see Figure $7 \mathrm{~b}, \mathrm{c}$ ).

Further tuning of harmonic spectra is observed in the array consisting of three $\mathrm{Fe}_{74} \mathrm{~B}_{13} \mathrm{Si}_{11} \mathrm{C}_{2}$ and one $\mathrm{Co}_{67} \mathrm{Fe}_{3.9} \mathrm{Ni}_{1.5} \mathrm{~B}_{11.5} \mathrm{Si}_{14.5} \mathrm{Mo}_{1.6}$ microwires (see Figure 8). The hysteresis loop of such array, consisting of three magnetically bistable microwires and one microwire with inclined hysteresis loop, is essentially nonlinear and has a complex shape (see Figure 8a).

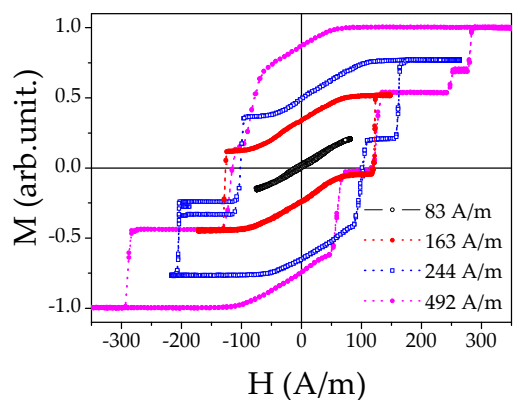

(a)

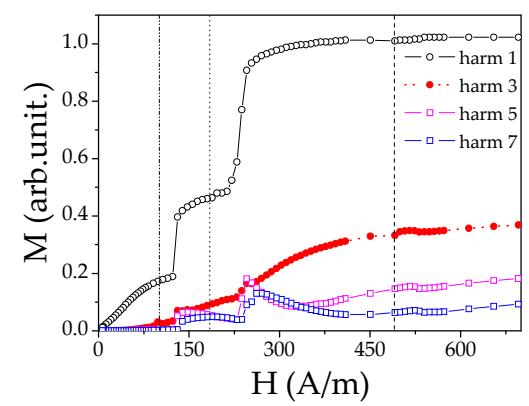

(b)

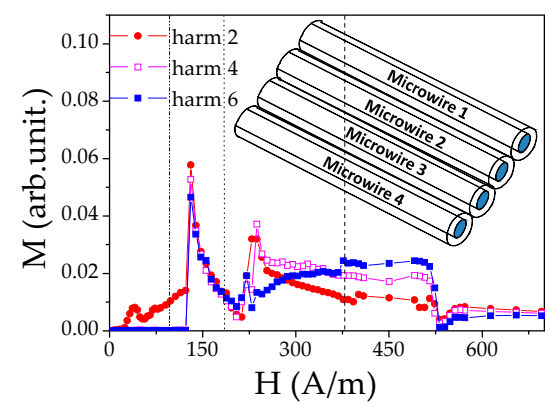

(c)

Figure 8. Hysteresis loops of four-wires system consisting of three $\mathrm{Fe}_{74} \mathrm{~B}_{13} \mathrm{Si}_{11} \mathrm{C}_{2}$ microwires and a $\mathrm{Co}_{67} \mathrm{Fe}_{3.9} \mathrm{Ni}_{1.5} \mathrm{~B}_{11.5} \mathrm{Si}_{14.5} \mathrm{Mo}_{1.6}$ microwire (a); odd and even harmonics vs. $H_{0}$ are given in $(\mathbf{b}, \mathbf{c})$, respectively. The schematic picture of the microwires array is provided in the inset of (c). Reprinted with permission from [51].

Basically, the hysteresis loop observed in low $H_{0}$ region is similar to those of a single Co-rich microwire (see Figure 8a). The superposition of a linear hysteresis loop and three rectangular hysteresis loops with three Barkhausen jumps is observed with increasing $H_{0}$ (see Figure 8a). 
The harmonic spectra also reflect the multistep magnetization process of the array consisting of four microwires with different hysteresis loops with regions of gradual changes and abrupt jumps (see Figure $8 b, c$ ).

Thus, the use of arrays consisting of magnetic microwires allows us to create a complex and unique spectra of magnetic harmonics in magnetic microwires.

One of the main features of magnetically bistable amorphous microwires is that such microwires behave similarly to single-domain magnets. Such behavior is linked to perfectly rectangular hysteresis loops of Fe-rich microwires (see Figures 4a and 9a) and the magnetostatic interaction described above. Accordingly, the hysteresis loops of a single magnetically bistable microwire and of the array of magnetically bistable microwires are substantially different. In the case of a single $\mathrm{Fe}_{65} \mathrm{Si}_{15} \mathrm{~B}_{15} \mathrm{C}_{5}$ microwire and arrays consisting of 2, 5, and $10 \mathrm{Fe}_{65} \mathrm{Si}_{15} \mathrm{~B}_{15} \mathrm{C}_{5}$ microwires, the hysteresis loops are rather different (see Figure 9).

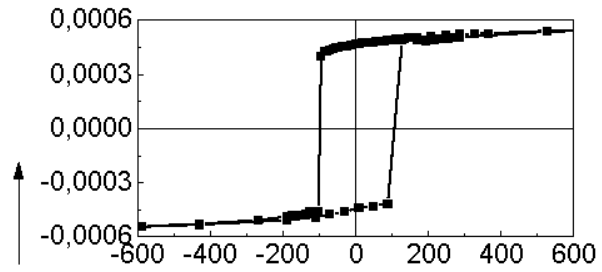

(a)

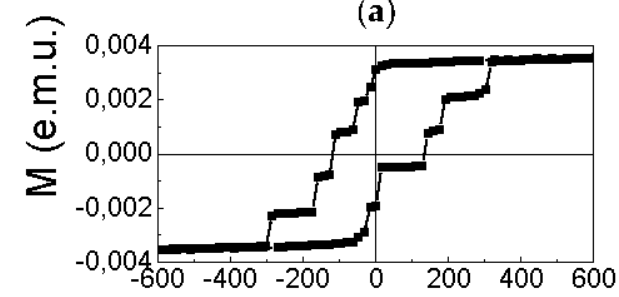

(c)

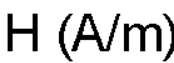

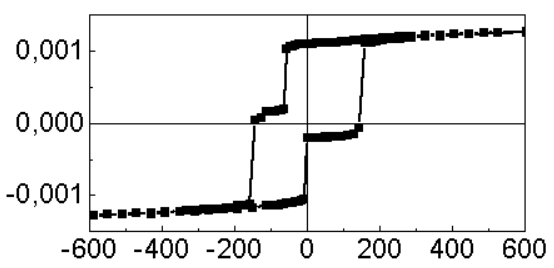

(b)

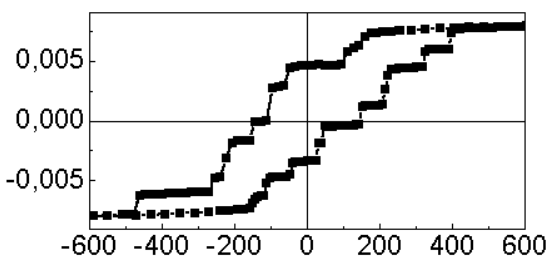

(d)

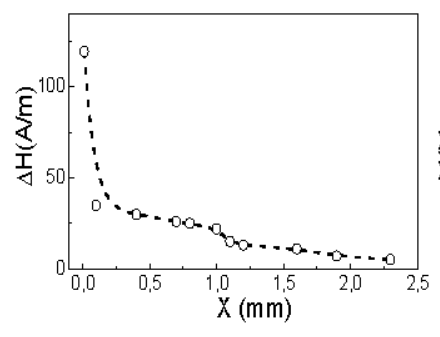

(e)

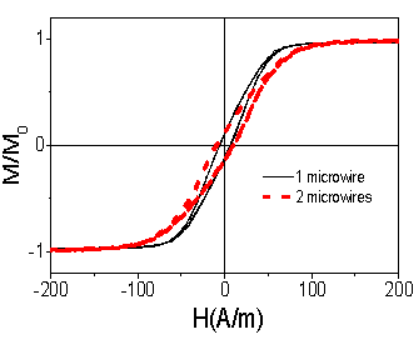

(f)

Figure 9. Hysteresis loops of a single glass-coated $\mathrm{Fe}_{65} \mathrm{Si}_{15} \mathrm{~B}_{15} \mathrm{C}_{5}$ amorphous microwire $(d=12.6 \mu \mathrm{m})$ (a) and of arrays consisting of $2(\mathbf{b}), 5$ (c), and 10 (d) $\mathrm{Fe}_{65} \mathrm{Si}_{15} \mathrm{~B}_{15} \mathrm{C}_{5}$ microwires, dependence of the hysteresis loop splitting on the distance between $\mathrm{Fe}_{65} \mathrm{Si}_{15} \mathrm{~B}_{15} \mathrm{C}_{5}$ microwires in the two-microwires array (e), and hysteresis loop of the array consisting of two $\mathrm{Co}_{67} \mathrm{Fe}_{3.9} \mathrm{Ni}_{1.5} \mathrm{~B}_{11.5} \mathrm{Si}_{14.5} \mathrm{Mo}_{1.6}$ glass-coated microwires (f). The line in (e) is just a guide to the eyes; (a-e) are reprinted with permission from [55]; (f) is reprinted with permission from [50].

The hysteresis loops shown in Figure 9 have been obtained when the microwires in the array were placed touching each other: the distance between the magnetic nucleuses was equal to the double glass-coating thickness $(7.4 \mu \mathrm{m})$. For a single microwire, a single Barkhausen jump is observed (Figure 9a). An increase in the number of microwires causes an increase in the number of jumps (see Figure $9 \mathrm{~b}-\mathrm{d}$ ) that correlates with the number of microwires.

As discussed above, the different $H_{s}$-values of the two jumps are explained by the influence of the stray field on the magnetization reversal in the array of a pair of microwires. The hysteresis loop splitting, $\Delta H$, defined as the difference between $H_{s 2}$ and $H_{s 1}$, depends on the distance between the microwires (see Figure 9e). At a distance of about $2 \mathrm{~mm}$, such splitting becomes negligible (Figure 9e). It is worth mentioning that such 
magnetostatic interaction in Co-rich microwires with inclined hysteresis loops is not quite pronounced. Thus, the presence of the second $\mathrm{Co}_{67} \mathrm{Fe}_{3.9} \mathrm{Ni}_{1.5} \mathrm{~B}_{11.5} \mathrm{Si}_{14.5} \mathrm{Mo}_{1.6}$ microwire in two $\mathrm{Co}_{67} \mathrm{Fe}_{3.9} \mathrm{Ni}_{1.5} \mathrm{~B}_{11.5} \mathrm{Si}_{14.5} \mathrm{Mo}_{1.6}$ microwires array causes a slight increase in the effective anisotropy field (see Figure 9f). The hysteresis loop shape remains almost the same.

\subsection{Multi-Bit Magnetic Tags Applications of Magnetic Microwires}

Hysteresis loops with several sharp jumps, observed in magnetically bistable microwire arrays, seem to be suitable for multi-bit magnetic tags. Such magnetic tags, consisting of several magnetically bistable microwires and presenting an overall hysteresis loop with several Barkhausen jumps, have been proposed for the magnetic codification method $[25,27,56]$. In such a magnetic tag, exposed to an $A C$ magnetic field, each particular microwire is remagnetized in a different magnetic field, giving rise to an electrical signal on the detection system (see Figure 10).

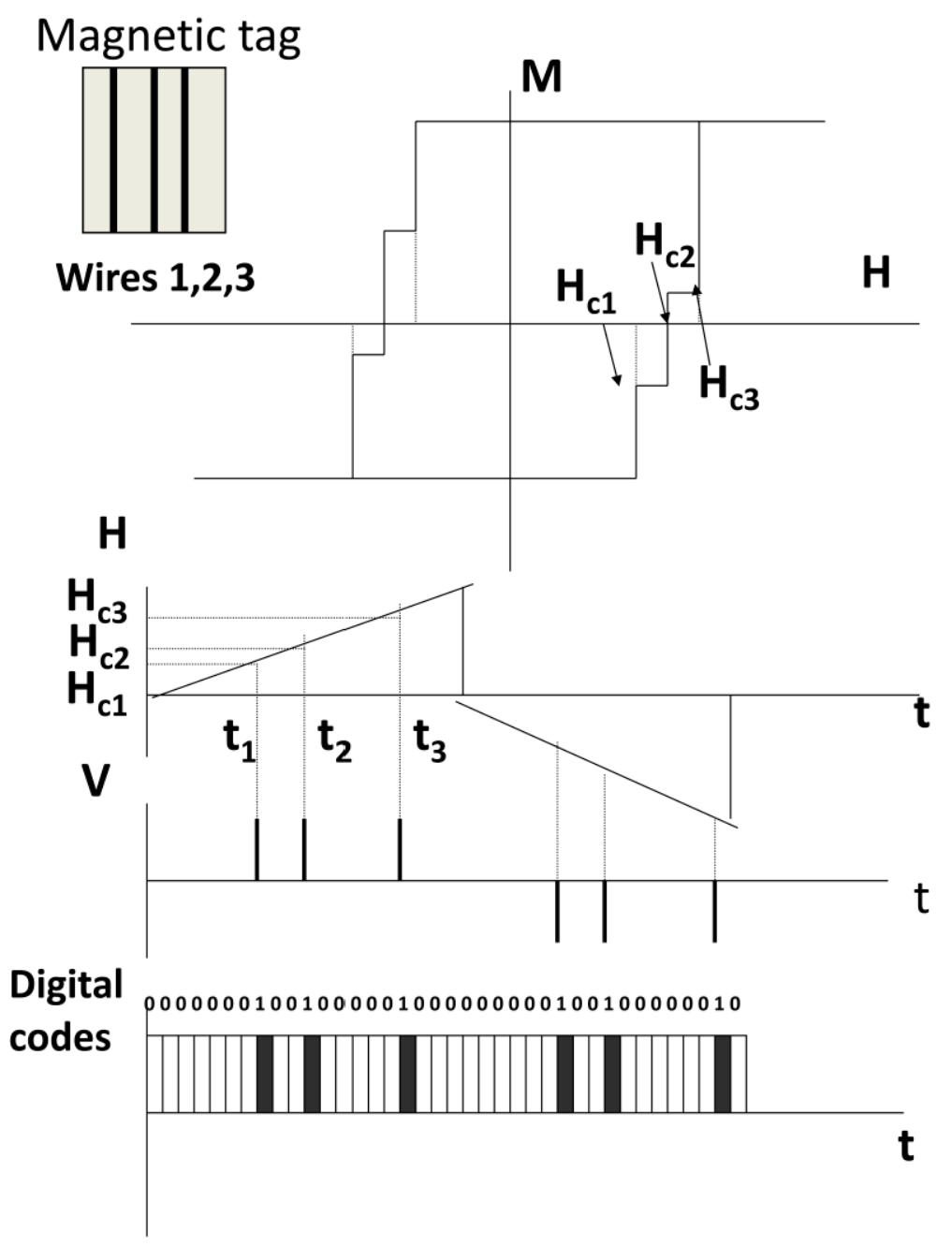

Figure 10. Schematic representation of the encoding system based on magnetic bistability of the microwires. Reprinted with permission from [56].

In a magnetic tag consisting of magnetically bistable microwires of the same composition, the hysteresis loop splitting, among other factors, is substantially affected by the distance between microwires. Therefore, multi-bit magnetic tags consisting of magnetically bistable microwires with rather different switching fields are considered more suitable for such application $[25,56]$. The extended range of switching fields provides a possibility to use a large number of combinations for magnetic codification. 
A variety of $H_{s}$-values can be achieved either by compositional $H_{s}$ dependence or by the effect of internal stress or thermal treatments on $H_{s}$.

The influence of chemical composition on the $H_{s}$-values of amorphous microwires is originated by the compositional dependence of $\lambda_{s}$ : a decrease in $\lambda_{s}$ is observed in $\mathrm{Fe}_{\mathrm{x}} \mathrm{Co}_{1-\mathrm{x}}$ amorphous alloys upon doping Fe-rich microwires with $\lambda_{s} \approx 40 \times 10^{-6}$ for $\mathrm{x}=1$, by Co up to $\lambda_{s} \sim-(5-3) \times 10^{-6}$ for $\mathrm{x}=0$ [57-59]. Similarly, a decrease in $\lambda_{s}$ is reported in $\mathrm{Fe}_{\mathrm{x}} \mathrm{Ni}_{1-\mathrm{x}}$ alloys with an increase in $\mathrm{Ni}$ content $[59,60]$.

A tendency of decrease in coercivity in $\mathrm{Fe}_{\mathrm{x}} \mathrm{Co}_{1-\mathrm{x}}$-based amorphous microwires can be appreciated from Figure 4, where the coercivity, $H_{c}$, drops from $H_{c} \approx 100 \mathrm{~A} / \mathrm{m}$ for $\mathrm{Fe}_{75} \mathrm{~B}_{9} \mathrm{Si}_{12} \mathrm{C}_{4}\left(\lambda_{s} \approx 40 \times 10^{-6}\right)$ up to $H_{c} \approx 5 \mathrm{~A} / \mathrm{m}$ for $\mathrm{Co}_{67} \mathrm{Fe}_{3.9} \mathrm{Ni}_{1.5} \mathrm{~B}_{11.5} \mathrm{Si}_{14.5} \mathrm{Mo}_{1.6} \mathrm{mi}-$ crowire $\left(\lambda_{s} \approx-0.5 \times 10^{-6}\right)$. The other example illustrating $H_{s}$ compositional dependence is shown in Figure 11, where hysteresis loops of $\mathrm{Fe}_{77.5} \mathrm{Si}_{7.5} \mathrm{~B}_{15}\left(\lambda_{s} \approx 38 \times 10^{-6}\right)$, $\mathrm{Fe}_{47.4} \mathrm{Ni}_{26.6} \mathrm{Si}_{11} \mathrm{~B}_{13} \mathrm{C}_{2}\left(\lambda_{s} \approx 20 \times 10^{-6}\right)$, and $\mathrm{Fe}_{16} \mathrm{Co}_{60} \mathrm{Si}_{13} \mathrm{~B}_{11}\left(\lambda_{s} \approx 15 \times 10^{-6}\right)$ microwires are shown.

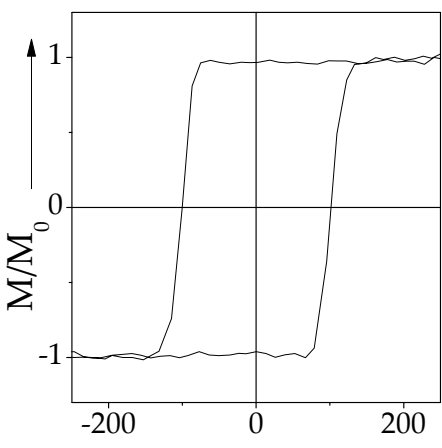

(a)

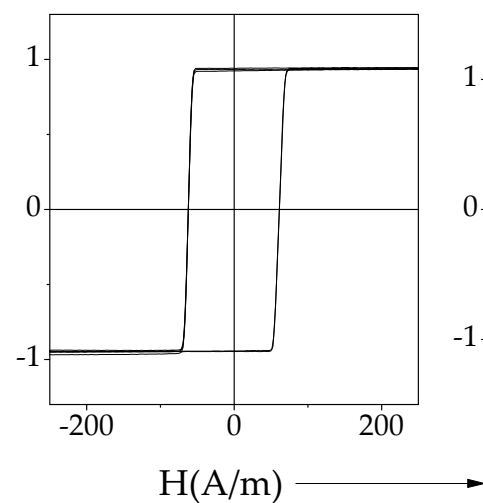

(b)

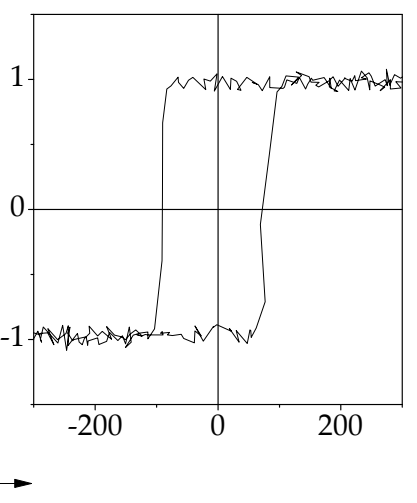

(c)

Figure 11. Hysteresis loops of as-prepared $\mathrm{Fe}_{77.5} \mathrm{Si}_{7.5} \mathrm{~B}_{15}$ (a), $\mathrm{Fe}_{47.4} \mathrm{Ni}_{26.6} \mathrm{Si}_{11} \mathrm{~B}_{13} \mathrm{C}_{2}$ (b), and $\mathrm{Fe}_{16} \mathrm{Co}_{60} \mathrm{Si}_{13} \mathrm{~B}_{11}$ (c) microwires. Reprinted with permission from [60]. Copyright (C) $2021 \mathrm{MDPI}$ Publishing, Open Access.

The lower coercivity of $\mathrm{Fe}_{47.4} \mathrm{Ni}_{26.6} \mathrm{Si}_{11} \mathrm{~B}_{13} \mathrm{C}_{2}$ and $\mathrm{Fe}_{16} \mathrm{Co}_{60} \mathrm{Si}_{13} \mathrm{~B}_{11}$ microwires as compared with $\mathrm{Fe}_{77.5} \mathrm{Si}_{7.5} \mathrm{~B}_{15}$ microwire correlates with lower $\lambda_{s}$-values (see Figure 11).

However, even for microwires with fixed chemical composition, the $H_{s}$-values can be tuned by the internal stresses, $\sigma_{i}$, values. The main (though, not the unique) origin of the internal stresses in glass-coated microwires is the different thermal expansion coefficients of the metallic nucleus and the glass coating [36,61-64]. Accordingly, it is assumed (and experimentally confirmed) that $\sigma_{i}$-magnitude inside the metallic nucleus is affected by the $\rho$-ratio between the metallic nucleus diameter, $d$, and the total microwire diameter, $D(\rho=d / D)[36,62-64]$.

As can be appreciated from Figure 12, even for the same microwire composition, $H_{s}$ can be modified by almost an order of magnitude (from 85 to $630 \mathrm{~A} / \mathrm{m}$ ) by changing the $\rho$-ratio. The correlation of $H_{s}$ and $\rho$-ratio is evidenced by the $H_{s}(\rho)$ shown in Figure 12e. 

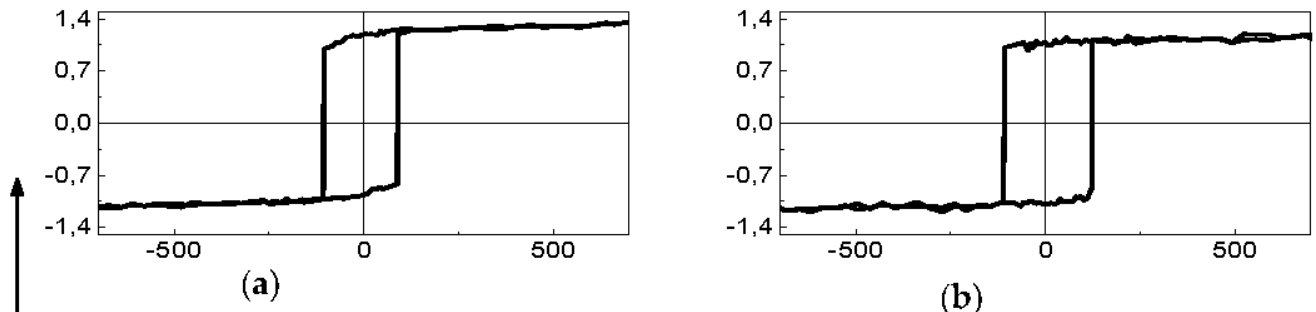

(b)

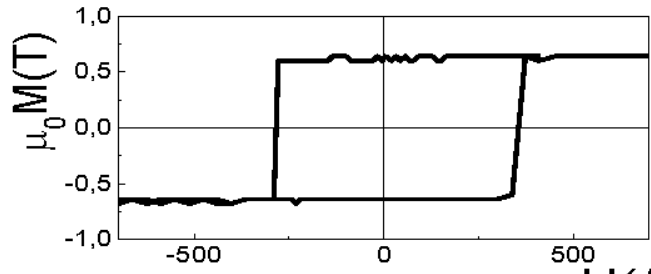

(c)

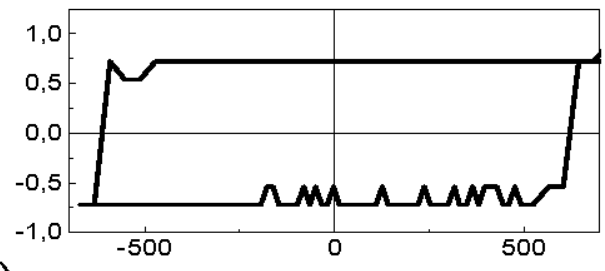

(d)

(e)

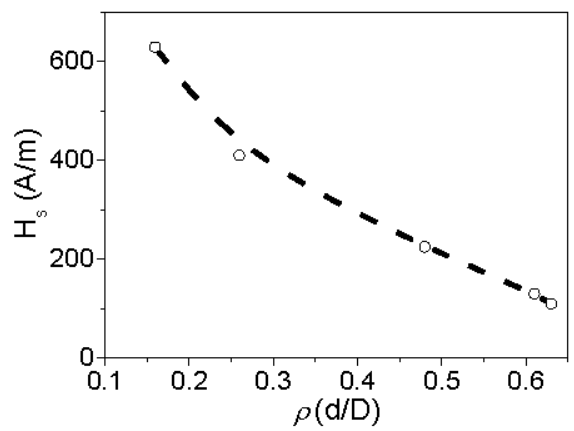

Figure 12. Hysteresis loops of $\mathrm{Fe}_{70} \mathrm{~B}_{15} \mathrm{Si}_{10} \mathrm{C}_{5}$ amorphous microwires with different metallic nucleus diameters, $d$, and total diameters, $D$ : with $\rho=0.63 ; d=15 \mu \mathrm{m}(\mathbf{a}) ; \rho=0.48 ; d=10.8 \mu \mathrm{m}(\mathbf{b}) ; \rho=0.26 ; d=6 \mu \mathrm{m}(\mathbf{c}) ; \rho=0.16 ; d=3 \mu \mathrm{m}(\mathbf{d})$, and $H_{s}(\rho)$ dependence of the same microwires (e). The line in (e) is just a guide to the eyes. Adapted from [63]. Figure 7 Copyright $(C$ 2021 MDPI Publishing, Open Access.

The main problem with magnetic tags consisting of microwires with different $d$-values is that the magnetic moments of microwires with different $d$-values are rather different. Accordingly, the alternative approach lies in the use of heat treatment allowing internal stresses relaxation keeping the magnetization values the same.

For the $\mathrm{Fe}_{75} \mathrm{~B}_{9} \mathrm{Si}_{12} \mathrm{C}_{4}$ microwires, annealing is not very effective: annealing allows only a slight $H_{S}$ decrease (see Figure $3 \mathrm{a}-\mathrm{c}$ ).

Annealing is the more effective route for $H_{s}$ tuning in $\mathrm{Fe}_{62} \mathrm{Ni}_{15.5} \mathrm{Si}_{7.5} \mathrm{~B}_{15}$ and $\mathrm{Fe}_{49.6} \mathrm{Ni}_{27.9}$ $\mathrm{Si}_{7.5} \mathrm{~B}_{15}$ microwires with positive magnetostriction $\left(\lambda_{s} \approx 27 \times 10^{-6}\right.$ and $20 \times 10^{-6}$, respectively) $[61,65,66]$.

As-prepared $\mathrm{Fe}_{62} \mathrm{Ni}_{15.5} \mathrm{Si}_{7.5} \mathrm{~B}_{15}$ and $\mathrm{Fe}_{49.6} \mathrm{Ni}_{27.9} \mathrm{Si}_{7.5} \mathrm{~B}_{15}$ microwires present rectangular hysteresis loops (see Figures 13a and 14a), as expected for microwires with positive $\lambda_{s}$-values (about $27 \times 10^{-6}$ and $20 \times 10^{-6}$, respectively). The rectangular character of the hysteresis loop is maintained for all annealed $\mathrm{Fe}_{62} \mathrm{Ni}_{15.5} \mathrm{Si}_{7.5} \mathrm{~B}_{15}$ and $\mathrm{Fe}_{49.6} \mathrm{Ni}_{27.9} \mathrm{Si}_{7.5} \mathrm{~B}_{15}$ microwires (at $T_{\text {ann }}=410^{\circ} \mathrm{C}$ ) (see Figures 13 and 14). However, a remarkable increase in $H_{s}$ is observed in both Fe-Ni-based microwires upon annealing (see Figures $13 \mathrm{~b}-\mathrm{d}$ and $14 \mathrm{~b}-\mathrm{d}$ ). 


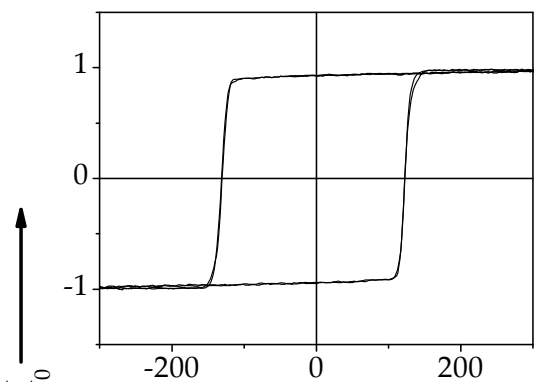

(a)

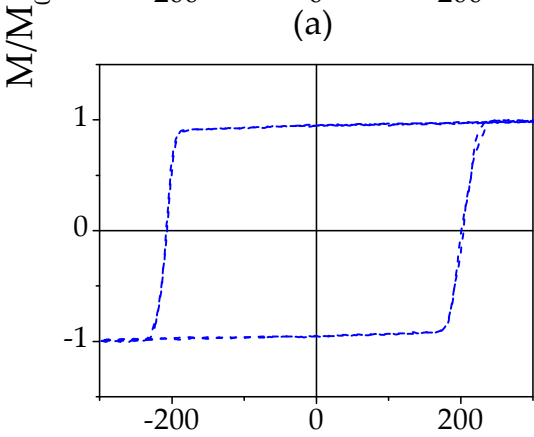

(c)

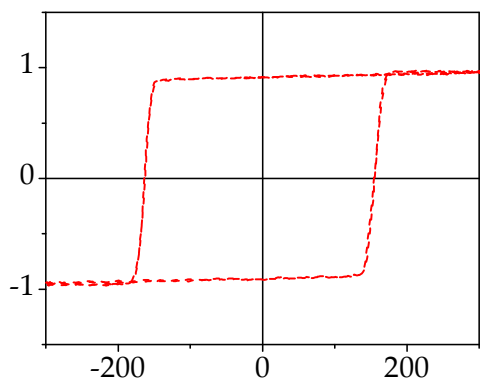

(b)

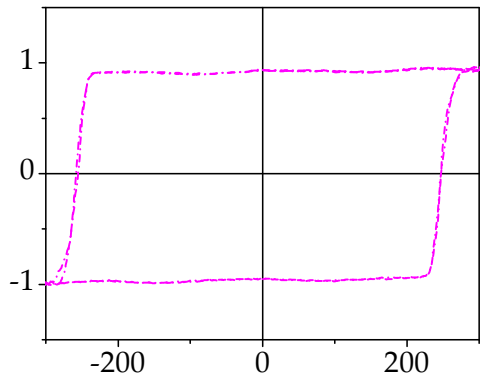

(d)

Figure 13. Hysteresis loops of as-prepared (a) and annealed for $4 \mathrm{~min}(\mathbf{b}), 16 \min (\mathbf{c})$, and $32 \mathrm{~min}(\mathbf{d})$ $\mathrm{Fe}_{62} \mathrm{Ni}_{15.5} \mathrm{Si}_{7.5} \mathrm{~B}_{15}$ microwires.

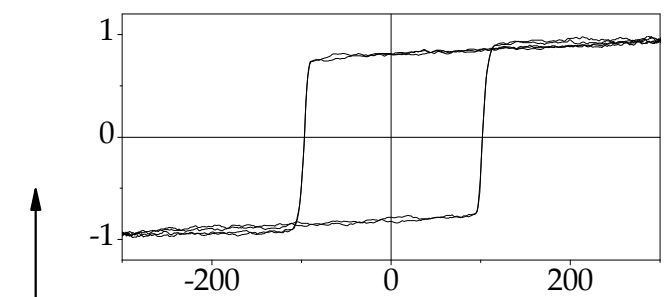

(a)

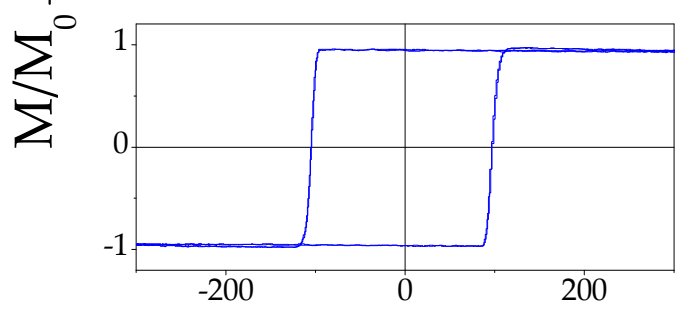

(c) $\mathrm{H}(\mathrm{A} / \mathrm{m})$

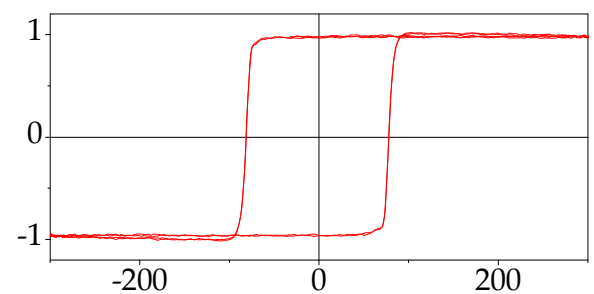

(b)

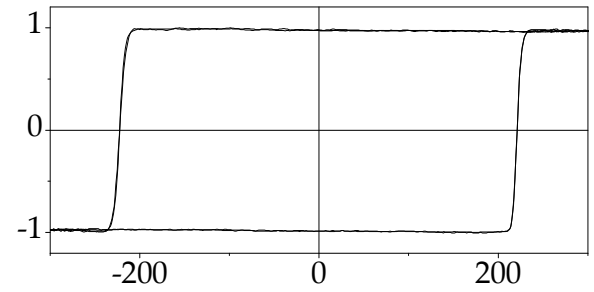

(d)

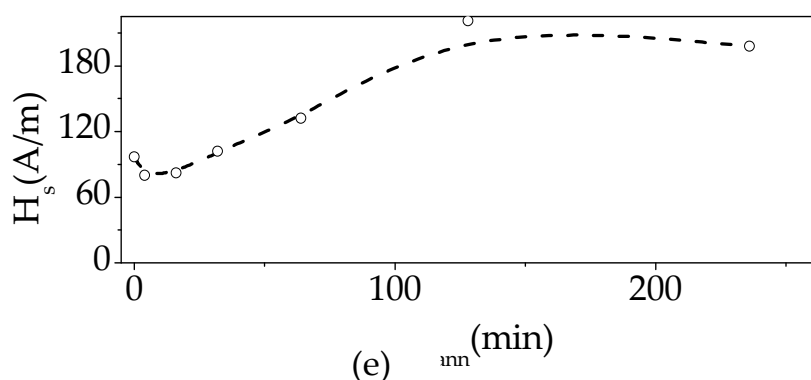

Figure 14. Hysteresis loops of as-prepared (a) and annealed at $T_{a n n}=410{ }^{\circ} \mathrm{C}$ for $t_{a n n}=4 \mathrm{~min}(\mathbf{b}), 32 \mathrm{~min}(\mathbf{c}), 128 \mathrm{~min}(\mathrm{~d})$, and $H_{c}\left(t_{\text {ann }}\right)$ dependence (e) for $\mathrm{Fe}_{49.6} \mathrm{Ni}_{27.9} \mathrm{Si}_{7.5} \mathrm{~B}_{15}$ microwires. The lines in (e) are just a guide to the eyes. (Reproduced with permission from [63]. Figure 11 Copyright (C) 2021 MDPI Publishing, Open Access). 
The magnetic hardening, observed in Fe-Ni-based amorphous microwires upon annealing, has been explained considering the effect of DW stabilization [60,65-68]. The mechanism of such DW stabilization is linked to directional atomic pair ordering along a preferred magnetization direction during the annealing and is usually observed for amorphous alloys with two or more ferromagnetic elements [60]. The nonmonotonic $H_{c}\left(t_{\text {ann }}\right)$ dependence (see Figure 14e) was explained in terms of the simultaneous effect of internal stresses relaxation (allowing a decrease in $H_{c}$ ) and DW stabilization (leading to an increase in $H_{c}$ ) $[65,66]$.

The observed possibility to tune coercivity of Fe-Ni-based microwires by annealing makes them suitable for multi-bit tags applications.

Even a wider range of coercivities can be achieved by partial or complete devitrification of amorphous microwires. The main attractive feature of nanocrystalline materials is their magnetic softening upon nanocrystallization $[17,60]$. Such magnetic softening is commonly attributed to the mixed amorphous nanocrystalline (average grain size of 10-15 nm) structure of properly annealed amorphous Fe-based alloys doped by $\mathrm{Cu}$ and $\mathrm{Nb}[17,60,69]$. Such nanocrystalline FeSiBCuNb alloys are commonly known as Finemet [60,69]. More recently, another family of nanocrystalline FeCoB-M-Cu (Hitperm) alloys has been proposed [69].

From the viewpoint of tags applications, the main advantage of nanocrystalline alloys is the high saturation magnetization [60,69-74].

As shown in Figure 15, as-prepared Finemet-like and Hitperm-like glass-coated microwires also present perfectly rectangular hysteresis loops. In the present case, the $\mathrm{Fe}_{38.5} \mathrm{Co}_{38.5} \mathrm{~B}_{18} \mathrm{Mo}_{4} \mathrm{Cu}_{1}$ microwire presents a nanocrystalline structure in the as-prepared state $[70,71]$. The advantage of as-prepared nanocrystalline materials is that they can present better mechanical properties [70,72]. On the other hand, a rectangular hysteresis loop can be observed in nanocrystalline microwires devitrified by annealing of an amorphous precursor [70,74]. Thus, a rectangular hysteresis loop with $H_{c} \approx 2000 \mathrm{~A} / \mathrm{m}$ is observed in $\mathrm{Fe}_{71,8} \mathrm{Cu}_{1} \mathrm{Nb}_{3,1} \mathrm{Si}_{15} \mathrm{~B}_{9,1}$ microwire $(\rho=0.282)$ annealed at $T_{\text {ann }}=700{ }^{\circ} \mathrm{C}$ (see Figure 16a).

In several cases, partial devitrification also allows to obtain peculiar step-wise hysteresis loops $[74,75]$. Such two-jump-like hysteresis loop observed in $\mathrm{Fe}_{71,8} \mathrm{Cu}_{1} \mathrm{Nb}_{3,1} \mathrm{Si}_{15} \mathrm{~B}_{9,1}$ microwire $(\rho=0.467)$ (see Figure 16b) has been explained by mixed amorphous—crystalline (bi-phase) structure [74].

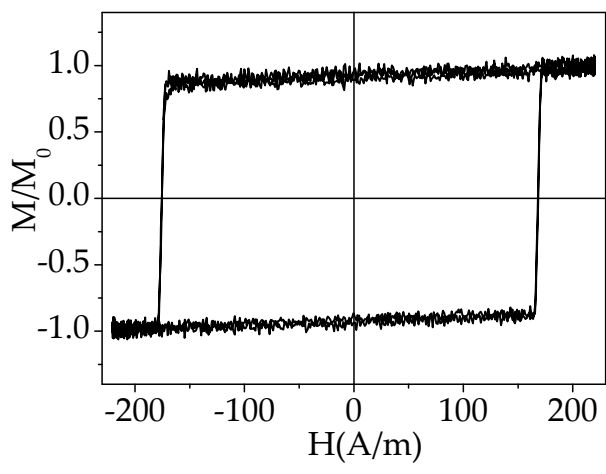

(a)

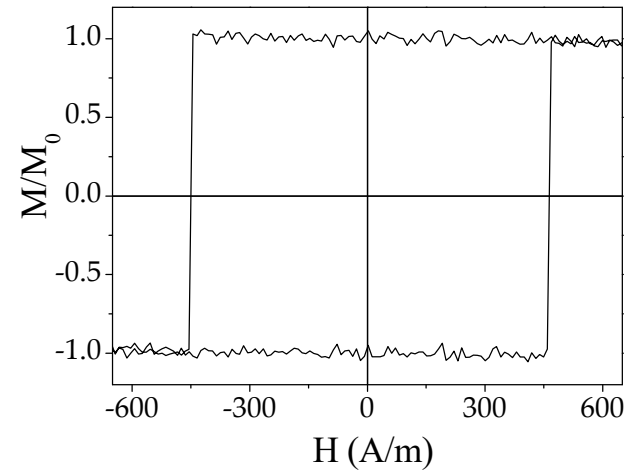

(b)

Figure 15. Hysteresis loops of as-prepared $\mathrm{Fe}_{70.8} \mathrm{Cu}_{1} \mathrm{Nb}_{3.1} \mathrm{Si}_{14.5} \mathrm{~B}_{10.6}(\rho=0.38)$ (a) and $\mathrm{Fe}_{38.5} \mathrm{Co}_{38.5} \mathrm{~B}_{18} \mathrm{Mo}_{4} \mathrm{Cu}_{1}(\rho=0.6)(\mathbf{b})$ microwires. Adapted from [70,71], respectively. 


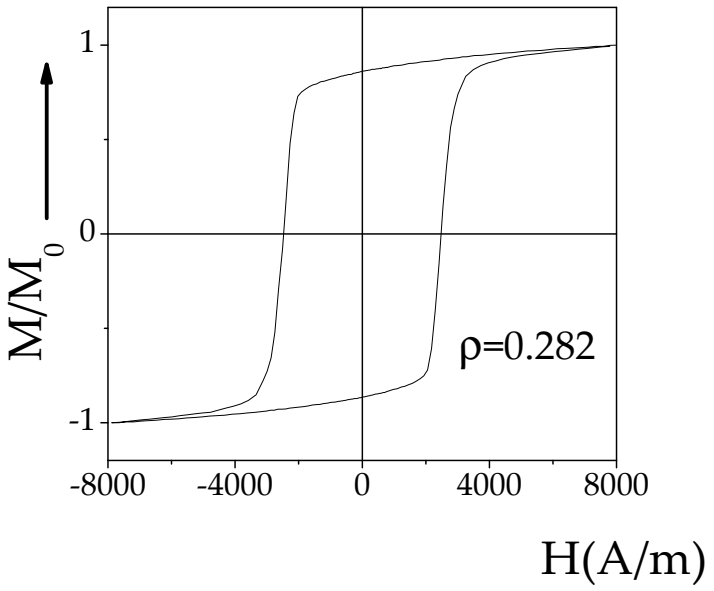

(a)

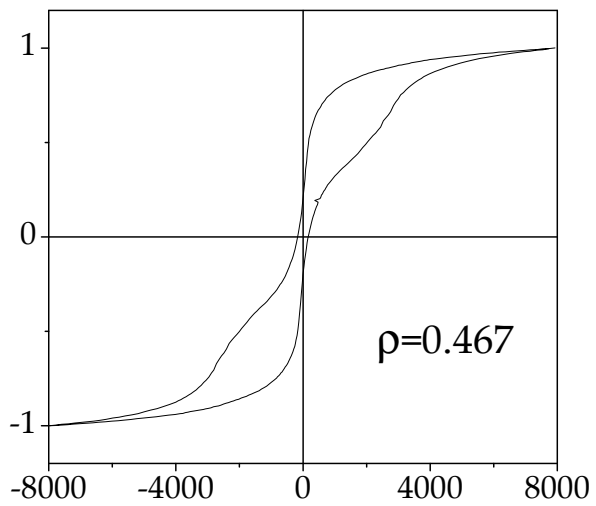

(b)

Figure 16. Hysteresis loops of $\mathrm{Fe}_{71,8} \mathrm{Cu}_{1} \mathrm{Nb}_{3,1} \mathrm{Si}_{15} \mathrm{~B}_{9,1}$ microwires with $\rho=0.282$ (a) and $\rho=0.467$ (b) annealed at $700{ }^{\circ} \mathrm{C}$. Adapted from [74].

Accordingly, an alternative route allowing to avoid the problems with high-precision tag design is the development of partially devitrified microwires presenting multi-step hysteresis loops [74-76].

The second magnetic phase can also be created on the glass shell. Accordingly, bimagnetic glass-coated microwires consisting of glass-coated microwire surrounded by an external magnetic microtube have been reported $[77,78]$. However, such technology requires one more technological process related to precise sputtering or electroplating of the magnetic microtube $[77,78]$. Considering thousands of security systems and millions of tags required for such applications on a daily basis, such a technological scheme can be challenging.

The above-described magnetostatic interaction between various microwires requires certain precision and special attention to magnetic multi-bit tag design. Accordingly, appropriate digital algorithms have been developed for the multi-bit tag recognition [26]. Additionally, the magnetization process of microwire arrays with different geometrical configurations has been analyzed theoretically by considering dipole-dipole interaction [79-81].

On the other hand, magnetically hard and semihard microwires are required for the development of smart markers for the electronic article surveillance [82]. A semihard magnetic material is proposed as a "deactivating element". When the deactivating element is magnetized, it creates a stray magnetic field that saturates the neighboring soft magnetic element, making the soft magnetic element undetectable by the interrogator used in the interrogation zone.

One of the routes allowing magnetic hardening is the use of Fe-Pt-based microwires and proper annealing, allowing the formation of an L10-type superstructure [83]. Elevated coercivity, $H_{c} \approx 40 \mathrm{kA} / \mathrm{m}$, has been achieved in properly annealed $\mathrm{Fe}_{50} \mathrm{Pt}_{40} \mathrm{Si}_{10}$ microwires upon devitrification of the amorphous precursor (see Figure 17).

Several alternative routes allowing magnetic hardening include controllable crystallization of Co- or Fe-rich microwires by Joule heating [84,85], by directional crystallization [86], by conventional furnace annealing [74], or by employing novel chemical compositions [87]. 


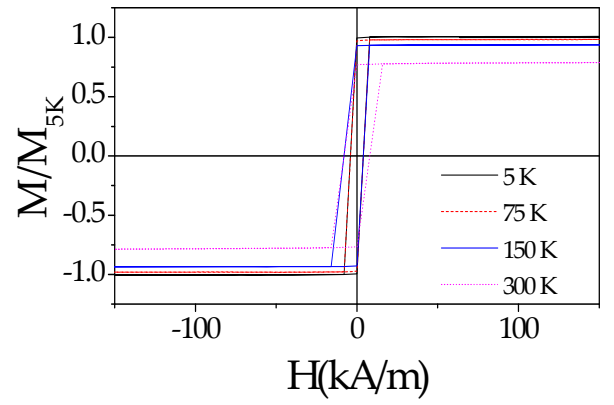

(a)

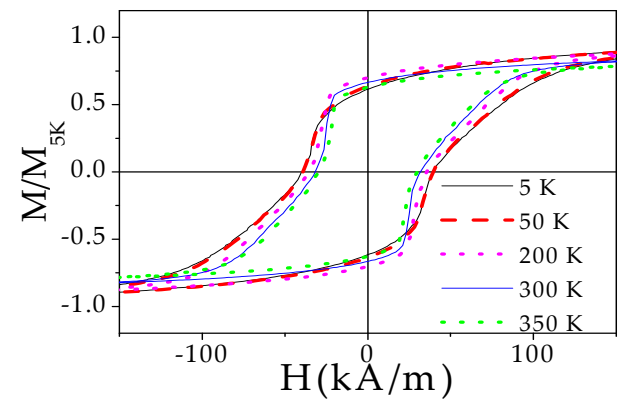

(b)

Figure 17. Hysteresis loops of as-prepared (a) and annealed at $500{ }^{\circ} \mathrm{C}$ for $1 \mathrm{~h} \mathrm{(b)} \mathrm{Fe}_{50} \mathrm{Pt}_{40} \mathrm{Si}_{10}$ microwires measured at different temperatures. Adapted from [83].

Provided routes for the design of nonlinear hysteresis loops allow us to consider amorphous and devitrified $\mathrm{Fe}-$, $\mathrm{Co}-\mathrm{Fe}-, \mathrm{Fe}-\mathrm{Ni}-$, and $\mathrm{Fe}-\mathrm{Pt}$-rich microwires as quite promising candidates for the use in security and electronic surveillance applications. We were able to tune the switching field of magnetically bistable microwires, by chemical composition of the metallic nucleus, by the internal stresses value (through the glass-coating thickness), by heat treatment as well as by magnetostatic interaction between magnetic microwires (through the magnetic field dependencies of even and odd harmonics). A predictable design of nonlinear hysteresis loops can serve as a good basis for magnetic tags application using glass-coated microwires.

\section{Conclusions}

We overviewed the properties of soft magnetic glass-coated microwires and the routes allowing to obtain nonlinear hysteresis loops either by different postprocessing or by using magnetostatic interaction between the microwires, making them quite attractive for electronic article surveillance and security applications.

The feasibility studies show that the fifth harmonics of $3 \mathrm{~cm}$ long typical Fe-rich microwire can be detected at a distance up to $25 \mathrm{~cm}$.

We showed that the presence of neighboring microwire (either Fe- or Co-based) significantly affects the hysteresis loop of the whole microwires array. In a microwires array containing magnetically bistable microwires, we observed splitting of the initially rectangular hysteresis loop with a number of Barkhausen jumps correlated with the number of magnetically bistable microwires. Essentially, nonlinear and irregular hysteresis loops have been observed in mixed arrays containing Fe- and Co-rich microwires. The observed nonlinear hysteresis loops allowed to increase the harmonics and to tune their magnetic field dependencies.

Nonlinear hysteresis loops have been also observed upon devitrification of amorphous microwires.

On the other hand, several routes allowing to tune the switching field by either postprocessing or modifying the magnetoelastic anisotropy have been reviewed.

The observed unique combination of magnetic properties, together with thin dimensions and excellent mechanical and anticorrosive properties, provide excellent perspectives for the use of glass-coated microwires for security and electronic surveillance applications.

Author Contributions: Conceptualization, A.Z. and V.Z.; methodology, M.I., J.M.B. and V.Z.; validation, A.Z.; formal analysis, A.Z. and V.Z.; investigation, A.Z., P.C.-L. and V.Z.; resources, A.Z. and J.G.; data curation, V.Z., P.C.-L., J.M.B. and M.I.; writing-original draft preparation, A.Z., P.C.-L. and V.Z.; writing-review and editing, A.Z., P.C.-L. and V.Z.; supervision, A.Z.; funding acquisition, A.Z., J.G. and V.Z. All authors have read and agreed to the published version of the manuscript.

Funding: This work was funded by Spanish MCIU under PGC2018-099530-B-C31 (MCIU/AEI/FEDER, UE) by the Government of the Basque Country under PIBA 2018-44 project and Elkartek (CEMAP 
and AVANSITE) projects and by the University of Basque Country under the scheme of "Ayuda a Grupos Consolidados" (Ref.: GIU18/192).

Institutional Review Board Statement: Not applicable.

Informed Consent Statement: Not applicable.

Data Availability Statement: The data presented in this study are available on request from the corresponding author. The data are not publicly available due to the restrictions associated with the conditions of projects under development.

Acknowledgments: The authors thank for technical and human support provided by SGIker of UPV /EHU (Medidas Magnéticas Gipuzkoa) and European funding (ERDF and ESF).

Conflicts of Interest: The authors declare no conflict of interest.

\section{References}

1. Lenz, J.; Edelstein, A.S. Magnetic sensors and their applications. IEEE Sens. J. 2006, 6, 631-649. [CrossRef]

2. Díaz-Michelena, M. Small Magnetic Sensors for Space Applications. Sensors 2009, 9, 2271-2283. [CrossRef]

3. Ripka, P.; Vertesy, G. Sensors based on soft magnetic materials Panel discussion. J. Magn. Magn. Mater. 2000, 215, 795-799. [CrossRef]

4. Fiorillo, F.; Bertotti, G.; Appino, C.; Pasquale, M. Soft Magnetic Materials. In Wiley Encyclopedia of Electrical and Electronics Engineering; Webster, J., Ed.; John Wiley \& Sons, Inc.: Torino, Italy, 1999; p. 42. [CrossRef]

5. Larin, V.S.; Torcunov, A.V.; Zhukov, A.; González, J.; Vazquez, M.; Panina, L. Preparation and properties of glass-coated microwires. J. Magn. Magn. Mater. 2002, 249/1-2, 39-45. [CrossRef]

6. Herzer, G. Magnetic materials for electronic article surveillance. J. Magn. Magn. Mater. 2003, 254-255, 598-602. [CrossRef]

7. Brauer, S.F.; Lebeau, T.; Strom-Olsen, J. Deactivating Element for Magnetic Marker and Method of Making Same. U.S. Patent 6,774,793, 10 August 2004.

8. Rudkowski, P.; Rudkowska, G.; Strom-Olsen, J.O. The fabrication of fine metallic fibers by continuous melt extraction and their magnetic and mechanical properties. Mater. Sci. Eng. A 1991, 133, 158-161. [CrossRef]

9. Schuh, C.A.; Hufnagel, T.C.; Ramamurty, U. Mechanical behavior of amorphous alloys. Acta Mater. 2007, 55, 4067-4109. [CrossRef]

10. Hagiwara, M.; Inoue, A.; Masumoto, T. Mechanical properties of Fe-Si-B amorphous wires produced by in-rotating-water spinning method. Metall. Trans. A 1982, 13, 373-382. [CrossRef]

11. Goto, T.; Nagano, M.; Wehara, N. Mechanical properties of amorphous $\mathrm{Fe}_{80} \mathrm{P}_{16} \mathrm{C}_{3} \mathrm{~B}_{1}$ filament produced by glass-coated melt spinning. Trans. JIM 1977, 18, 759-764. [CrossRef]

12. Zhukova, V.; Cobeño, A.F.; Zhukov, A.; de Arellano Lopez, A.R.; López-Pombero, S.; Blanco, J.M.; Larin, V.; Gonzalez, J. Correlation between magnetic and mechanical properties of devitrified glass-coated $\mathrm{Fe}_{71.8} \mathrm{Cu}_{1} \mathrm{Nb}_{3.1} \mathrm{Si}_{15} \mathrm{~B}_{9.1}$ microwires. J. Magn . Magn. Mater. 2002, 249, 79-84. [CrossRef]

13. Nabias, J.; Asfour, A.; Yonnet, J.-P. Effect of Torsion Stress on the Offset and Sensitivity of Diagonal and Off-Diagonal GMI in Amorphous Wires. Sensors 2018, 18, 4121. [CrossRef] [PubMed]

14. Morón, C.; Cabrera, C.; Morón, A.; García, A.; González, M. Magnetic Sensors Based on Amorphous Ferromagnetic Materials: A Review. Sensors 2015, 15, 28340-28366. [CrossRef] [PubMed]

15. Herrero-Gomez, C.; Marın, P.; Hernando, A. Bias free magnetomechanical coupling on magneticmicrowires for sensing applications. Appl. Phys. Lett. 2013, 103, 142414. [CrossRef]

16. Mohri, K.; Uchiyama, T.; Panina, L.V.; Yamamoto, M.; Bushida, K. Recent Advances of Amorphous Wire CMOS IC MagnetoImpedance Sensors: Innovative High-Performance Micromagnetic Sensor Chip. J. Sens. 2015. [CrossRef]

17. Hasegawa, R. Applications of Amorphous Magnetic Alloys. In Properties and Applications of Nanocrystalline Alloys from Amorphous Precursors; NATO Science Series (Series II: Mathematics, Physics and Chemistry); Idzikowski, B., Švec, P., Miglierini, M., Eds.; Springer: Dordrecht, The Netherlands, 2005; Volume 184, pp. 189-198.

18. Honkura, Y.; Honkura, S. The Development of ASIC Type GSR Sensor Driven by GHz Pulse Current. Sensors 2020, $20,1023$. [CrossRef]

19. Sabol, R.; Klein, P.; Ryba, T.; Hvizdos, L.; Varga, R.; Rovnak, M.; Sulla, I.; Mudronova, D.; Galik, J.; Polacek, I.; et al. Novel Applications of Bistable Magnetic Microwires. Acta Phys. Pol. A 2017, 131, 1150-1152. [CrossRef]

20. Zhukov, A.; Cobeño, A.F.; Gonzalez, J.; Blanco, J.M.; Aragoneses, P.; Dominguez, L. Magnetoelastic sensor of level of the liquid based on magnetoelastic properties of Co-rich microwires. Sens. Actuat. A Phys. 2000, 81/1-3, 129-133. [CrossRef]

21. Mohri, K.; Humphrey, F.B.; Kawashima, K.; Kimura, K.; Muzutani, M. Large Barkhausen and Matteucci Effects in FeCoSiB, FeCrSiB, and FeNiSiB Amorphous Wires. IEEE Trans. Magn. 1990, 26, 1789-1791. [CrossRef]

22. Zhukova, V.; Zhukov, A.; Blanco, J.M.; Gonzalez, J.; Ponomarev, B.K. Switching field fluctuations in a glass coated Fe-rich amorphous microwire. J. Magn. Magn. Mater. 2002, 249, 131-135. [CrossRef]

23. Soeda, M.; Takajo, M.; Yamasaki, J.; Humphrey, F.B. Large Barkhausen Discontinuities of Die-Drawn Fe-Si-B Amorphous Wire. IEEE Trans. Magn. 1995, 31, 3877-3879. [CrossRef] 
24. Von Gutfeld, R.J.; Dicello, J.F.; McAllister, S.J.; Ziegler, J.F. Amorphous magnetic wires for medical locator applications. Appl. Phys. Lett. 2002, 81, 1913-1915. [CrossRef]

25. Zhukov, A. Glass-Coated magnetic microwires for technical applications. J. Magn. Magn. Mater. 2002, 242-245, 216-223. [CrossRef]

26. Makhnovskiy, D.; Fry, N.; Zhukov, A. On different tag reader architectures for bistable microwires. Sens. Actuat. A Phys. 2011, 166, 133-140. [CrossRef]

27. Larin, V.; Torcunov, A.; Baranov, S.; Vázquez, M.; Zhukov, A.; Hernando, A. Method of Magnetic Codification and Marking of the Objects. Spain Patent P9,601,993, 20 September 1996.

28. Ho, W.K.; Yamasaki, J. Article Surveillance Magnetic Marker Having an Hysteresis Loop with Large Barkhausen Discontinuities at a Low Field Threshold Level. U.S. Patent 5,801,630, 1 September 1998.

29. Humphrey, F.; Yamasaki, J.; Deactivatable, E.A.S. Marker Having a Step Change in Magnetic Flux. U.S. Patent 4,980,670, 25 December 1990.

30. Chen, D.-X.; Dempsey, N.M.; Vázquez, M.; Hernando, A. Propagating domain wall shape and dynamics in iron-rich amorphous wires. IEEE Trans. Magn. 1995, 31, 781-790. [CrossRef]

31. Vazquez, M.; Chen, D.-X. The magnetization reversal process in amorphous wires. IEEE Trans. Magn. 1995, 31, 1229-1238. [CrossRef]

32. Zhukova, V.; Blanco, J.M.; Chizhik, A.; Ipatov, M.; Zhukov, A. AC-current-induced magnetization switching in amorphous microwires. Front. Phys. 2018, 13, 137501. [CrossRef]

33. Ogasawara, I.; Ueno, S. Preparation and properties of amorphous wires. IEEE Trans. Magn. 1995, 31, 1219-1223. [CrossRef]

34. Chiriac, H.; Lupu, N.; Stoian, G.; Ababei, G.; Corodeanu, S.; Óvári, T.-A. Ultrathin nanocrystalline magnetic wires. Crystals 2017, 7, 48. [CrossRef]

35. Corte-Leon, P.; Zhukova, V.; Ipatov, M.; Blanco, J.M.; González, J.; Churyukanova, M.; Taskaev, S.; Zhukov, A. The effect of annealing on magnetic properties of "Thick" microwires. J. Alloys Compd. 2020, 831, 150992. [CrossRef]

36. Baranov, S.A.; Larin, V.S.; Torcunov, A.V. Technology, Preparation and Properties of the Cast Glass-Coated Magnetic Microwires. Crystals 2017, 7, 136. [CrossRef]

37. Kozejova, D.; Fecova, L.; Klein, P.; Sabol, R.; Hudak, R.; Sulla, I.; Mudronova, D.; Galik, J.; Varga, R. Biomedical applications of glass-coated microwires. J. Magn. Magn. Mater. 2019, 470, 2-5. [CrossRef]

38. Praslička, D.; Blažek, J.; Šmelko, M.; Hudák, J.; Čverha, A.; Mikita, I.; Varga, R.; Zhukov, A. Possibilities of Measuring Stress and Health Monitoring in Materials Using Contact-Less Sensor Based on Magnetic Microwires. IEEE Trans. Magn. 2013, 49, 128-131. [CrossRef]

39. Allue, A.; Corte-León, P.; Gondra, K.; Zhukova, V.; Ipatov, M.; Blanco, J.M.; Gonzalez, J.; Churyukanova, M.; Taskaev, S.; Zhukov, A. Smart composites with embedded magnetic microwire inclusions allowing non-contact stresses and temperature monitoring. Compos. Part A Appl. Sci. Manuf. 2019, 120, 12-20. [CrossRef]

40. Talaat, A.; Alonso, J.; Zhukova, V.; Garaio, E.; García, J.A.; Srikanth, H.; Phan, M.H.; Zhukov, A. Ferromagnetic glass-coated microwires with good heating properties for magnetic hyperthermia. Sci. Rep. 2016, 6, 39300. [CrossRef]

41. Mitxelena-Iribarren, O.; Campisi, J.; Martínez de Apellániz, I.; Lizarbe-Sancha, S.; Arana, S.; Zhukova, V.; Mujika, M.; Zhukov, A. Glass-coated ferromagnetic microwire-induced magnetic hyperthermia for in vitro cancer cell treatment. Mater. Sci. Eng. C 2020, 106, 110261. [CrossRef]

42. Qin, F.X.; Peng, H.X.; Phan, M.H.; Panina, L.V.; Ipatov, M.; Zhukov, A. Effects of wire properties on the field-tunable behaviour of continuous-microwire composites. Sens. Actuator A Phys. 2012, 178, 118-125. [CrossRef]

43. Ulitovsky, A.V.; Avernin, N.M. Method of Fabrication of Metallic Microwire. Bulletin No. 7. USSR Patent No. 161325,19 March 1964.

44. Kraus, L.; Schneider, J.; Wiesner, H. Ferromagnetic resonance in amorphous alloys prepared by rapid quenching from the melt. Czech. J. Phys. B 1976, 26, 601-602. [CrossRef]

45. Zhukov, A.; Ipatov, M.; Talaat, A.; Blanco, J.M.; Hernando, B.; Gonzalez-Legarreta, L.; Suñol, J.J.; Zhukova, V. Correlation of Crystalline Structure with Magnetic and Transport Properties of Glass-Coated Microwires. Crystals 2017, 7, 41. [CrossRef]

46. Gonzalez-Legarreta, L.; Corte-Leon, P.; Zhukova, V.; Ipatov, M.; Blanco, J.M.; Gonzalez, J.; Zhukov, A. Optimization of magnetic properties and GMI effect of Thin Co-rich Microwires for GMI Microsensors. Sensors 2020, 20, 1558. [CrossRef]

47. Gudoshnikov, S.; Usov, N.; Zhukov, A.; Zhukova, V.; Palvanov, P.; Ljubimov, B.; Serebryakova, O.; Gorbunov, S. Evaluation of use of magnetically bistable microwires for magnetic labels. Phys. Status Solidi A 2011, 208, 526-529. [CrossRef]

48. Gudoshnikov, S.; Usov, N.; Ignatov, A.; Tarasov, V.; Zhukov, A.; Zhukova, V. Ferromagnetic Microwire Usage for Magnetic Tags. In Proceedings of the PIERS Proceedings, Moscow, Russia, 19-23 August 2012; pp. 1274-1277.

49. Zhukova, V.; Blanco, J.M.; Ipatov, M.; Churyukanova, M.; Taskaev, S.; Zhukov, A. Tailoring of magnetoimpedance effect and magnetic softness of Fe-rich glass-coated microwires by stress-annealing. Sci. Rep. 2018, 8, 3202. [CrossRef] [PubMed]

50. Rodionova, V.; Ipatov, M.; Ilyn, M.; Zhukova, V.; Perov, N.; Gonzalez, J.; Zhukov, A. Design of magnetic properties of arrays of magnetostatically coupled glass-covered magnetic microwires. Phys. Status Solidi A 2010, 207, 1954-1959. [CrossRef]

51. Rodionova, V.; Ipatov, M.; Ilyn, M.; Zhukova, V.; Perov, N.; Panina, L.; Gonzalez, J.; Zhukov, A. Magnetostatic interaction of glass-coated magnetic microwires. J. Appl. Phys. 2010, 108, 016103. [CrossRef]

52. Zhukov, A.; Vázquez, M.; Velázquez, J.; Garcia, C.; Valenzuela, R.; Ponomarev, B. Frequency dependence of coercivity in rapidly quenched amorphous materials. J. Mat. Sci. Eng. A 1997, 226-228, 753-756. [CrossRef] 
53. Talaat, A.; Del Val, J.J.; Zhukova, V.; Ipatov, M.; Klein, P.; Varga, R.; Gonzalez, J.; Zhdanova, M.; Churyukanova, M.; Zhukov, A. Effect of annealing on magnetic properties of nanocrystalline Hitperm-type glass-coated microwires. J. Alloys Compd. 2016, 660, 297-303. [CrossRef]

54. Zhukov, A.; Gómez-Polo, C.; Crespo, P.; Vázquez, M. Axial and transverse magnetization processes of glass-coated amorphous microwires. J. Magn. Magn. Mater. 1996, 157/158, 143-144. [CrossRef]

55. Chizhik, A.; Zhukov, A.; Blanco, J.M.; Szymczak, R.; Gonzalez, J. Interaction between Fe-rich ferromagnetic glass coated microwires. J. Magn. Magn. Mater. 2002, 249/1-2, 99-103. [CrossRef]

56. Zhukov, A.; González, J.; Blanco, J.M.; Vázquez, M.; Larin, V. Microwires coated by glass: A new family of soft and hard magnetic materials. J. Mater. Res. 2000, 15, 2107-2113. [CrossRef]

57. Churyukanova, M.; Semenkova, V.; Kaloshkin, S.; Shuvaeva, E.; Gudoshnikov, S.; Zhukova, V.; Shchetinin, I.; Zhukov, A. Magnetostriction investigation of soft magnetic microwires. Phys. Status Solidi A 2016, 213, 363-367. [CrossRef]

58. Konno, Y.; Mohri, K. Magnetostriction measurements for amorphous wires. IEEE Trans. Magn. 1989, 25, 3623-3625. [CrossRef]

59. Herzer, G. Amorphous and nanocrystalline soft magnets. In Proceedings of the NATO Advanced Study Institute on Magnetic Hysteresis in Novel Materials, Mykonos, Greece, 1-12 July 1996; Hadjipanayis, G.C., Ed.; Kluwer Academic Publishers: Dordrecht, The Netherlands, 1997; Volume 338, pp. 711-730.

60. Zhukova, V.; Corte-Leon, P.; González-Legarreta, L.; Talaat, A.; Blanco, J.M.; Ipatov, M.; Olivera, J.; Zhukov, A. Review of Domain Wall Dynamics Engineering in Magnetic Microwires. Nanomaterials 2020, 10, 2407. [CrossRef] [PubMed]

61. Antonov, A.S.; Borisov, V.T.; Borisov, O.V.; Prokoshin, A.F.; Usov, N.A. Residual quenching stresses in glass-coated amorphous ferromagnetic microwires. J. Phys. D Appl. Phys. 2000, 33, 1161-1168. [CrossRef]

62. Chiriac, H.; Óvári, T.-A.; Corodeanu, S.; Ababei, G. Interdomain wall in amorphous glass-coated microwires. Phys. Rev. B 2007, 76, 214433. [CrossRef]

63. Zhukova, V.; Corte-Leon, P.; González-Legarreta, L.; Talaat, A.; Blanco, J.M.; Ipatov, M.; Olivera, J.; Zhukov, A. Optimization of Magnetic Properties of Magnetic Microwires by Post-Processing. Processes 2020, 8, 1006. [CrossRef]

64. Zhukova, V.; Blanco, J.M.; Ipatov, M.; Zhukov, A. Magnetoelastic contribution in domain wall dynamics of amorphous microwires. Phys. B 2012, 407, 1450-1454. [CrossRef]

65. Zhukova, V.; Talaat, A.; Corte-Leon, P.; Blanco, J.M.; Ipatov, M.; Zhukov, A. Engineering of magnetic properties and domain wall dynamics in Fe-Ni-based amorphous microwires by annealing. AIP Adv. 2020, 10, 015130. [CrossRef]

66. Zhukov, A.; Churyukanova, M.; Kaloshkin, S.; Semenkova, V.; Gudoshnikov, S.; Ipatov, M.; Talaat, A.; Blanco, J.M.; Zhukova, V. Effect of annealing on magnetic properties and magnetostriction coefficient of Fe-Ni-based amorphous microwires. J. Alloys Compd. 2015, 651, 718-723. [CrossRef]

67. Yamasaki, J.; Mohri, K.; Watari, K.; Narita, K. Domain wall induced anisotropy during annealing in amorphous ribbons. IEEE Trans. Magn. 1984, 20, 1855-1857. [CrossRef]

68. Kohmoto, O.; Ohya, K. Amorphous FeCo-SiB alloys with zero magnetostriction. J. Appl. Phys. 1981, 52, 928-932. [CrossRef]

69. McHenry, M.E.; Willard, M.A.; Laughlin, D.E. Amorphous and nanocrystalline materials for applications as soft magnets. Prog. Mater. Sci. 1999, 44, 291-433. [CrossRef]

70. Churyukanova, M.; Zhukova, V.; Talaat, A.; del Val, J.J.; Kaloshkin, S.; Kostitcyna, E.; Shuvaeva, E.; Sudarchikova, V.; Zhukov, A. Studies of thermal and magnetic properties of Fe-based amorphous and nanocrystalline glass coated microwires. J. Alloys Compd. 2014, 615, S256-S260. [CrossRef]

71. Zhukova, V.; Talaat, A.; Ipatov, M.; del Val, J.J.; Blanco, J.M.; Gonzalez-Legarreta, L.; Hernando, B.; Varga, R.; Klein, P.; Zhukov, A. Optimization of Soft Magnetic Properties in Nanocrystalline Fe-Rich Glass-Coated Microwires. JOM 2015, 67, $2108-2116$. [CrossRef]

72. Zhukova, V.; Ipatov, M.; Corte-Leon, P.; Blanco, J.M.; Zanaeva, E.; Bazlov, A.I.; Jiang, J.; Louzguine-Luzgin, D.V.; Olivera, J.; Zhukov, A. Excellent magnetic properties of $\left(\mathrm{Fe}_{0.7} \mathrm{Co}_{0.3}\right)_{83.7} \mathrm{Si}_{4} \mathrm{~B}_{8} \mathrm{P}_{3.6} \mathrm{Cu}_{0.7}$ ribbons and microwires. Intermetallics 2020, 117, 106660. [CrossRef]

73. Dudek, C.; Adenot-Engelvin, A.L.; Bertin, F.; Acher, O. Engineering of the magnetic properties of Finemet based nanocrystalline glass-coated microwires. J. Non-Cryst. Solids 2007, 353, 925-927. [CrossRef]

74. Zhukova, V.; Cobeño, A.F.; Zhukov, A.; Blanco, J.M.; Larin, V.; Gonzalez, J. Coercivity of glass-coated $\mathrm{Fe}_{73.4-\mathrm{x}} \mathrm{Cu}_{1} \mathrm{Nb}_{3.1} \mathrm{Si}_{13.4+} \times \mathrm{B}_{9.1}$ $(0 \leq \mathrm{x} \leq 1.6)$ microwires. Nanostruct. Mater. 1999, 11, 1319-1327. [CrossRef]

75. Baraban, I.; Gorshenkov, M.; Andreev, N.; Chichay, K.; Rodionova, V. The role of structural properties on magnetic characteristics of glass-coated microwires. J. Magn. Magn. Mater. 2018, 459, 61-65. [CrossRef]

76. Elmanov, G.N.; Chernavskii, P.A.; Kozlov, I.V.; Dzhumaev, P.S.; Kostitsyna, E.V.; Tarasov, V.P.; Ignatov, A.S.; Gudoshnikov, S.A. Effect of heat treatment on phase transformations and magnetization of amorphous $\mathrm{Co}_{69} \mathrm{Fe}_{4} \mathrm{Cr}_{4} \mathrm{Si}_{12} \mathrm{~B}_{11}$ microwires. J. Alloys Compd. 2018, 741, 648-655. [CrossRef]

77. Torrejon, J.; Infante, G.; Badini-Confalonieri, G.; Pirota, K.; Vazquez, M. Electroplated bimagnetic microwires: From processing to magnetic properties and sensor devices. JOM 2013, 65, 890. [CrossRef]

78. Iglesias, I.; El Kammouni, R.; Chichay, K.; Vazquez, M.; Rodionova, V. High temperature properties of CoFe/CoNi and Fe/CoNi biphase microwires. Solid State Phenom. 2015, 233, 265-268. [CrossRef]

79. Velazquez, J.; Vazquez, M. Spatial and temporal distributions of magnetisation in arrays of interacting bistable microwires. J. Magn. Magn. Mater. 2002, 249, 89-94. [CrossRef] 
80. Sampaio, L.C.; Sinnecker, E.H.C.P.; Cernicchiaro, G.R.C.; Knobel, M.; Vazquez, M.; Velazquez, J. Magnetic microwires as macrospins in a long-range dipole-dipole interaction. Phys. Rev. B 2000, 61, 8976-8983. [CrossRef]

81. Piccin, R.; Laroze, D.; Knobel, M.; Vargas, P.; Vázquez, M. Magnetostatic interactions between two magnetic wires. EPL 2007, 78, 67004. [CrossRef]

82. Cordery, R.A.; Murphy, C.F.M., III. Deactivatable Electronic Article Surveillance Markers Using Short Semi-Hard Magnetic Wires. U.S. Patent 5,191,315, 2 March 1993.

83. Zhukov, A.; Ipatov, M.; Talaat, A.; Aronin, A.; Abrosimova, G.; del Val, J.J.; Zhukova, V. Magnetic hardening of Fe-Pt and Fe-Pt-M (M=B, Si) microwires. J. Alloys Compd. 2018, 735, 1071-1078. [CrossRef]

84. Evstigneeva, S.A.; Nematov, M.G.; Omelyanchik, A.; Yudanov, N.A.; Rodionova, V.V.; Panina, L.V. Hard magnetic properties of Co-rich microwires crystallized by current annealing. IEEE Magn. Lett. 2020, 7, 7501305. [CrossRef]

85. Zhukova, V.; Cobeño, A.F.; Zhukov, A.; Blanco, J.M.; Puerta, S.; Gonzalez, J.; Vázquez, M. Tailoring of magnetic properties of glass coated microwires by current annealing. J. Non-cryst. Solids. 2001, 287, 31-36. [CrossRef]

86. Morchenko, A.T.; Panina, L.V.; Larin, V.S.; Churyukanova, M.N.; Salem, M.M.; Hashim, H.; Trukhanov, A.V.; Korovushkin, V.V.; Kostishyn, V.G. Structural and magnetic transformations in amorphous ferromagnetic microwires during thermomagnetic treatment under conditions of directional crystallization. J. Alloys Compd. 2017, 698, 685-691. [CrossRef]

87. Betancourt, I.; Zamora, J.; Jiménez, A.; del Real, R.P.; Vázquez, M. Rare earth-free hard magnetic microwires. Scr. Mater. 2018, 153, 40-43. [CrossRef] 